UNIVERSIDADE DE SÃO PAULO

ESCOLA DE ENFERMAGEM DE RIBEIRÃO PRETO

ARTUR ACELINO FRANCISCO LUZ NUNES QUEIROZ

Acesso à Profilaxia Pós-Exposição ao HIV: barreiras e possibilidades

RIBEIRÃO PRETO

2021 


\section{ARTUR ACELINO FRANCISCO LUZ NUNES QUEIROZ}

Acesso à Profilaxia Pós-Exposição ao HIV: barreiras e possibilidades

Tese apresentada para obtenção do título de Doutor em Ciências (dupla titulação), no âmbito do Convênio Acadêmico Internacional para Coorientação de tese de doutorado celebrado pela Escola de Enfermagem de Ribeirão Preto da Universidade de São Paulo e pela Escola Nacional de Saúde Pública da Universidade NOVA de Lisboa.

Linha de pesquisa: Fundamentação teórica, metodológica e tecnológica do processo de cuidar

Orientador: Isabel Amélia Costa Mendes

Co-orientador: Sônia Dias

RIBEIRÃO PRETO 
Autorizo a reprodução e divulgação total ou parcial deste trabalho, por qualquer meio convencional ou eletrônico, para fins de estudo e pesquisa, desde que citada a fonte.

Queiroz, Artur Acelino Francisco Luz Nunes

Acesso à Profilaxia Pós-Exposição ao HIV: barreiras e possibilidades. Ribeirão Preto, 2021.

53 p. : il. ; $30 \mathrm{~cm}$

Tese apresentada para obtenção do título de Doutor em Ciências (dupla titulação), no âmbito do Convênio Acadêmico Internacional para Coorientação de tese de doutorado celebrado pela Escola de Enfermagem de Ribeirão Preto da Universidade de São Paulo e pela Escola Nacional de Saúde Pública da Universidade NOVA de Lisboa. Área de concentração: Enfermagem Fundamental.

Orientador: Isabel Amélia Costa Mendes

Coorientador:Sônia Dias

1. Barreiras ao Acesso aos Cuidados de Saúde. 2. Infecções por HIV. 3.Profilaxia Pós-Exposição. 4.mHealth. 
QUEIROZ, Artur Acelino Francisco Luz Nunes

Acesso à Profilaxia Pós-Exposição ao HIV: barreiras e possibilidades

Tese apresentada para obtenção do título de Doutor em Ciências (dupla titulação), no âmbito do Convênio Acadêmico Internacional para Coorientação de tese de doutorado celebrado pela Escola de Enfermagem de Ribeirão Preto da Universidade de São Paulo e pela Escola Nacional de Saúde Pública da Universidade NOVA de Lisboa.

Aprovado em I /

\section{Presidente}

Prof. Dr.

Instituição:

Comissão Julgadora

Prof. Dr.

Instituição:

Prof. Dr.

Instituição:

Prof. Dr.

Instituição: 


\section{DEDICATÓRIA}

Dedico este trabalho a todos os profissionais de enfermagem que, trabalhando durante a Pandemia, perderam suas vidas.

Meus sinceros agradecimentos e admiração. 


\section{AGRADECIMENTOS}

Primeiramente a meus pais, Tulio e Celina, que me ensinaram como a educação é transformadora.

Aos meus familiares, em especial minha avó Auridete, meus tios e tias que mesmo com a distância nunca mediram esforços para me apoiar.

Profa. Isabel Amélia Costa Mendes, meus agradecimentos vão muito além dessa tese, mas para a vida. Seus ensinamentos, conselhos e atitudes irão comigo para onde quer que eu vá. A senhora foi a orientadora que eu sempre quis, me ensinando sempre com respeito e dedicação. Sua orientação me fez expandir meus horizontes e moldar meu futuro.

Profa. Sônia Dias, a senhora me recebeu de forma calorosa no frio inverno europeu, sempre disponível, me instigando a discussões e reflexões importantes, mas me acalmando nos momentos mais necessários. Lhe serei sempre grato.

Profa. Denise de Andrade, muito mais que uma professora, a senhora foi em muitos momentos uma segunda mãe para mim em Ribeirão Preto, sempre me fazendo me sentir em casa mesmo tão longe.

Aos amigos que o intercâmbio me proporcionou, Bia, Cecilia (Brasilia), Cecilia (Recife),

Debbie, Fernanda, Ed e Gabriel, Juliana, Larissa, Leonardo, Monica, Rubens, Renata e Suzana, nosso suporte mútuo foi fundamental para encarar os desafios do doutorado durante os momentos mais incertos.

Aos colegas do GEPECOPEN, em especial a Sara, Profa. Simone e Profa. Carla, pela convivência e trabalho em equipe.

À Universidade de São Paulo, pelo apoio durante minha formação.

À Universidade Nova de Lisboa, pelo suporte e ensino durante meu doutorado.

Ao Conselho Nacional de Desenvolvimento Científico e Tecnológico por financiar minha bolsa de doutorado, que me permitiu concluir meus estudos em dedicação integral.

O presente trabalho foi realizado com apoio da Coordenação de Aperfeiçoamento de Pessoal de Nível Superior - Brasil (CAPES) - Código de Financiamento 001. 


\section{EPÍGRAFE}

"I am not a beginning. I am not an end. I am a link in a chain."

— Keith Haring

"We need to tackle extreme inequality because it is morally indefensible and socially corrosive - undermining our health, affecting our well-being, and undermining peaceful societies."

-Winnie Byanyima 


\begin{abstract}
Queiroz, Artur Acelino Francisco Luz Nunes Queiroz. Access to HIV Post-Exposure Prophylaxis: Barriers and Possibilities. 2021. 53 f. Dissertation (Doctorate in Sciences) University of São Paulo at Ribeirão Preto College of Nursing, 2021.
\end{abstract}

Introduction: The number of HIV cases continues to rise globally, disproportionately in men who have sex with men and other vulnerable populations, despite the development of multiple prevention strategies. Among these strategies, HIV Post-Exposure Prophylaxis (PEP) stands out, although underutilized, is at the center of the prevention cascade. By following its protocol, users are tested and may be referred to prophylaxis, treatment (if necessary) and even offered to other strategies, thus being a multipotent tool for interrupting the HIV transmission chain. Thus, our study aimed to explore access to health services that offer Postexposure HIV Prophylaxis and the technologies available to help it. Methods: Two sequential steps were carried out: 1st - Exploratory and descriptive study with a qualitative approach and 2nd - Technology Prospection Study. The research followed the ethical guidelines on research with human beings, regulated by resolution 466/12 and approved by the Ethics and Research Committee of the Nursing School of Ribeirão Preto/USP (opinion $n^{\circ} 3.280,490$ ). The qualitative study aimed to explore the barriers to accessing HIV Post Exposure Prophylaxis perceived by users and professionals in specialized health services. For this, an exploratory research with a qualitative approach was carried out. The research participants were medical professionals and nurses involved in the prophylaxis protocol in Reference Centers and prevention users, totaling 10 participants, a sample defined by data saturation. The recorded interviews were transcribed and later processed by the Descending Hierarchical Classification and by Similitude analysis. The prospect was guided by the objective of identifying and analyzing mobile apps that address PEP for HIV infections. We conducted a descriptive exploratory study in 3 sequential phases: systematic literature review, patent analysis and systematic search of app stores. For the systematic review, we followed the Preferred Reporting Items guidelines for Systematic Reviews and Meta-Analyzes adapted for an integrative review in the PubMed, Web of Knowledge, Scopus, Cochrane, Embase, Science Direct, Eric, Treasure and CINAHL databases. Results: Five classes were obtained: Information; Access centralization; Service flow; Interpersonal relationships in health services and Difficulties and Barriers. There are several factors that hinder access to prevention that permeate knowledge, reception, and dissemination of information. With the advent of the COVID-19 pandemic, many of these problems are aggravated and increase the vulnerability of possible users of prophylaxis. In the search for technologies that would aid access to PEP, the apps found only inform about the prevention and treatment of HIV, targeting health professionals, people with HIV or the general population, but with only available resources limited, that is, mainly text, images, and videos. The three applications with an exclusive focus on PEP were created by researchers from Brazilian universities. Conclusion: Access to HIV post-exposure prophylaxis faces challenges and barriers, ranging from the lack of knowledge about prophylaxis, which makes it impossible to pursue it, to the centralization of health services and stigmas that permeate the structures of health services. Our review found no connection between scientific studies, registered patents, and available applications related to PEP; this finding indicates that these available applications do not have a theoretical or methodological basis in their creation.

Descriptors: HIV infections; Acquired Immunodeficiency Syndrome; Post-Exposure Prophylaxis; Barriers to Access to Health Care; eHealth; mHealth. 


\section{RESUMO}

Queiroz, Artur Acelino Francisco Luz Nunes Queiroz. Acesso à Profilaxia Pós-Exposição ao HIV: barreiras e possibilidades. 2021. 53f. Tese (Doutorado em Ciências) - Escola de Enfermagem de Ribeirão Preto, Universidade de São Paulo, Ribeirão Preto, 2021.

Introdução: O número de casos de HIV continua a aumentar globalmente, de forma desproporcional em homens que fazem sexo com homens e outras populações vulneráveis, apesar do desenvolvimento de múltiplas estratégias de prevenção. Dentre essas estratégias, destaca-se a Profilaxia Pós-Exposição ao HIV (PEP), ainda que subutilizada, se encontra no centro da cascata de prevenção. Ao seguir seu protocolo os usuários são levados a testagem, podendo ser encaminhados à profilaxia, ao tratamento (caso seja necessário) e até mesmo ofertados à outras estrategias, sendo assim uma ferramenta multipotente para a interrupção da cadeia de transmissão do HIV. Assim, nosso estudo teve como objetivo explorar o acesso aos serviços de saúde que ofertam a Profilaxia Pós exposição ao HIV e as tecnologias disponíveis para auxiliá-lo. Métodos: Foram realizadas duas etapas sequenciais: $1^{\mathrm{a}}$ - Estudo exploratório e descritivo com abordagem qualitativa e $2^{\mathrm{a}}$ - Estudo de Prospecção de Tecnologias. A pesquisa obedeceu às diretrizes éticas sobre pesquisas com seres humanos, reguladas pela resolução 466/12 e aprovado pelo Comitê de Ética e Pesquisa da Escola de Enfermagem de Ribeirão Preto/USP (parecer $n^{\circ} 3.280 .490$ ). O estudo qualitativo visou explorar as barreiras de acesso à Profilaxia Pós Exposição ao HIV percebidas por usuários e profissionais de saúde nos serviços de saúde especializados. Para isso foi realizada uma pesquisa exploratória com abordagem qualitativa. Os participantes da pesquisa foram profissionais médicos e enfermeiros envolvidos no protocolo da profilaxia em Centros de Referência e usuários da prevenção, totalizando 10 participantes, amostragem definida por saturação de dados. As entrevistas gravadas foram transcritas e posteriormente processadas pela Classificação Hierárquica Descendente e por análise de Similitude. A prospecção foi guiada pelo objetivo de identificar e analisar os aplicativos móveis que abordam PEP para infecções por HIV. Conduzimos um estudo exploratório descritivo em 3 fases sequenciais: revisão sistemática da literatura, análise de patentes e busca sistemática de lojas de aplicativos. Para a revisão sistemática, seguimos as diretrizes Preferred Reporting Items for Systematic Reviews and Meta-Analyzes adaptadas para uma revisão integrativa nas bases de dados PubMed, Web of Knowledge, Scopus, Cochrane, Embase, Science Direct, Eric, Treasure e CINAHL. Resultados: Foram obtidas cinco classes: Informação; Centralização de acesso; Fluxo de atendimento; Relações interpessoais nos serviços de saúde e Dificuldades e Barreiras. Existem diversos fatores dificultadores no acesso à prevenção que perpassam conhecimento, acolhimento e divulgação de informações. Diante do advento da Pandemia de COVID-19 muitos desses problemas se agravam e aumentam a vulnerabilidade de possíveis utilizadores da profilaxia. Na busca por tecnologias que auxiliassem o acesso a PEP, os aplicativos encontrados apenas informam sobre a prevenção e tratamento do HIV tendo como públicoalvo profissionais de saúde, pessoas com HIV ou a população em geral, mas com recursos disponíveis apenas limitados, isto é, principalmente texto, imagens e vídeos. Os três aplicativos com foco exclusivo no PEP foram criados por pesquisadores de universidades brasileiras. Conclusão: O acesso à profilaxia pós-exposição ao HIV encontra desafios e barreiras, que vão desde o desconhecimento sobre a profilaxia, o que impossibilita sua busca, à centralização dos serviços de saúde e estigmas que permeiam as estruturas dos serviços de saúde. Nossa revisão não encontrou nenhuma conexão entre os estudos científicos, patentes registradas e os aplicativos disponíveis relacionados ao PEP; esse achado indica que esses aplicativos disponíveis não possuem um embasamento teórico ou metodológico em $\mathrm{s}^{\prime}$ criação.

Descritores: Infecções por HIV; Síndrome de Imunodeficiência Adquirida; Profilaxia PósExposição; Barreiras ao Acesso aos Cuidados de Saúde; eHealth; mHealth. 


\section{RESUMEN}

Queiroz, Artur Luz Acelino Francisco Nunes Queiroz. Acceso a la profilaxis posexposición al VIH: barreras y posibilidades. 2021. XX 53.Tesis (Doctorado en Ciencias) - Escuela de Enfermería de Ribeirão Preto, Universidad de São Paulo, Ribeirão Preto, 2021.

Introducción: El número de casos de VIH sigue aumentando a nivel mundial, de manera desproporcionada en hombres que tienen sexo con hombres y otras poblaciones vulnerables, a pesar del desarrollo de múltiples estrategias de prevención. Entre estas estrategias, se destaca la profilaxis posexposición al VIH (PEP), aunque infrautilizada, está en el centro de la cascada de prevención. Siguiendo su protocolo, los usuarios son testeados y pueden ser referidos a profilaxis, tratamiento e incluso ofrecidos a otras estrategias, siendo así una herramienta multipotente para interrumpir la cadena de transmisión del VIH. Por lo tanto, nuestro estudio tuvo como objetivo explorar el acceso a los servicios de salud que ofrecen profilaxis del VIH posexposición y las tecnologías disponibles para ayudarlo. Métodos: Se realizaron dos pasos secuenciales: $1^{\circ}$ - Estudio exploratorio y descriptivo con enfoque cualitativo y $2^{\mathbf{o}}$ - Estudio de Prospección Tecnológica. La investigación siguió los lineamientos éticos sobre investigación con seres humanos, regulados por la resolución 466/12 y aprobados por el Comité de Ética e Investigación de la Escuela de Enfermería de Ribeirão Preto/USP (dictamen $n^{\circ}$ 3.280.490). El estudio cualitativo tuvo como objetivo explorar las barreras para acceder a la profilaxis posexposición al VIH percibidas por los usuarios y profesionales de los servicios de salud especializados. Para ello, se realizó una investigación exploratoria con enfoque cualitativo. Los participantes de la investigación fueron profesionales médicos y enfermeros involucrados en el protocolo de profilaxis en Centros de Referencia y usuarios de prevención, totalizando 10 participantes, muestra definida por saturación de datos. Las entrevistas grabadas fueron transcritas y posteriormente procesadas por la Clasificación Jerárquica Descendente y por el análisis de Similitud. La perspectiva se guió por el objetivo de identificar y analizar aplicaciones móviles que abordan la PEP para las infecciones por el VIH. Realizamos un estudio exploratorio descriptivo en 3 fases secuenciales: revisión sistemática de la literatura, análisis de patentes y búsqueda sistemática en tiendas de aplicaciones. Para la revisión sistemática, seguimos las pautas Preferred Reporting Items para revisiones sistemáticas y metaanálisis adaptadas para una revisión integradora en las bases de datos PubMed, Web of Knowledge, Scopus, Cochrane, Embase, Science Direct, Eric, Treasure y CINAHL. Resultados: Se obtuvieron cinco clases: Información; Centralización de acceso; Flujo de servicio; Relaciones interpersonales en los servicios de salud y Dificultades y Barreras. Son varios los factores que dificultan el acceso a la prevención que permean el conocimiento, la recepción y la difusión de información. Con el advenimiento de la pandemia de COVID-19, muchos de estos problemas se agravan y aumentan la vulnerabilidad de los posibles usuarios de profilaxis. En la búsqueda de tecnologías que faciliten el acceso a la PEP, las aplicaciones encontradas solo informan sobre la prevención y el tratamiento del VIH, dirigido a los profesionales de la salud, las personas con VIH o la población en general, pero con los recursos disponibles limitados. es decir, principalmente texto, imágenes y videos. Las 3 aplicaciones con un enfoque exclusivo en PEP fueron creadas por investigadores de universidades brasileñas. Conclusión: El acceso a la profilaxis posexposición al VIH enfrenta desafíos y barreras, que van desde el desconocimiento sobre la profilaxis, que imposibilita su persecución, hasta la centralización de los servicios de salud y los estigmas que permean las estructuras de los servicios de salud. Nuestra revisión no encontró conexión entre los estudios científicos, las patentes registradas y las aplicaciones disponibles relacionadas con la PEP; este hallazgo indica que estas aplicaciones disponibles no tienen una base teórica o metodológica en su creación.

Descriptores: Infecciones por VIH; Síndrome de inmunodeficiencia adquirida; La profilaxis posterior a la exposición; Barreras al acceso a la atención médica; eHealth; mHealth. 


\section{SUMÁRIO}

Sumário

1. INTRODUÇÃO

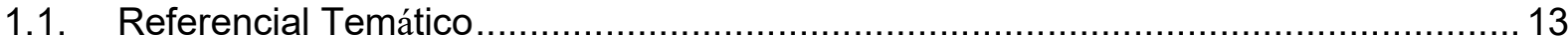

1.1.1. Estratégias de prevenção a infecção pelo HIV …............................................... 13

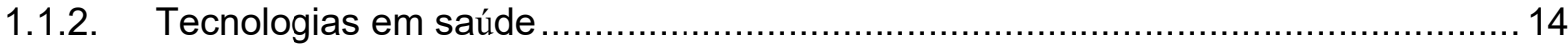

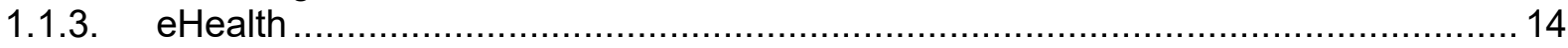

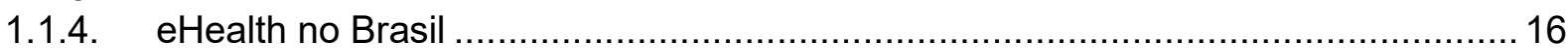

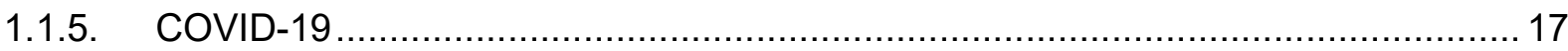

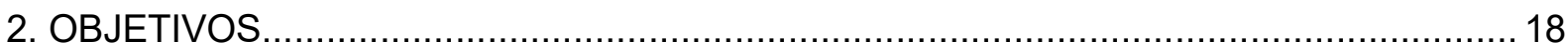

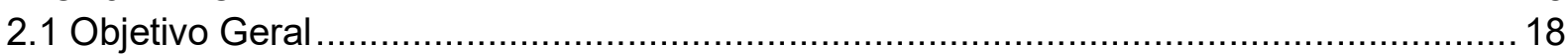

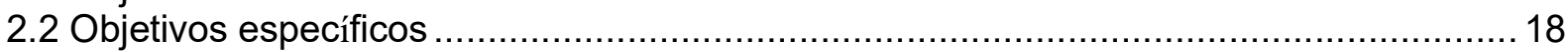

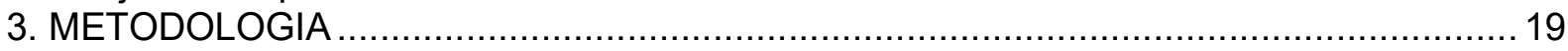

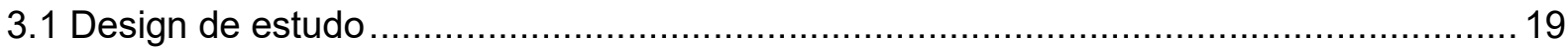

3.1.1. Etapa 1: Estudo exploratório e descritivo com abordagem qualitativa ....................... 19

3.1.2. Etapa 2: Estudo de Prospecção de Tecnologias................................................. 19

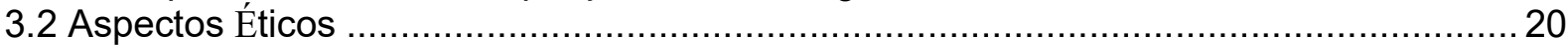

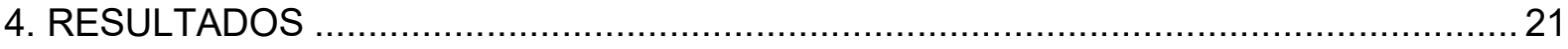

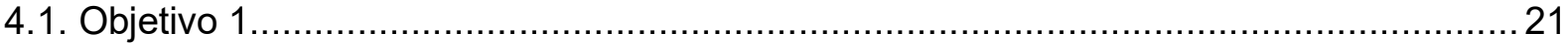

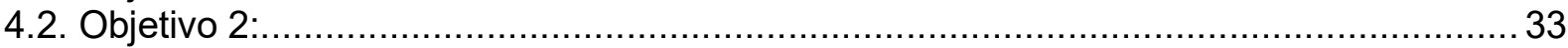

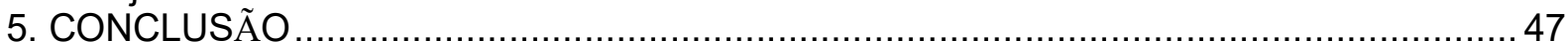

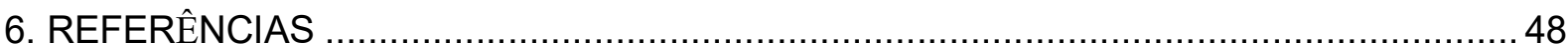

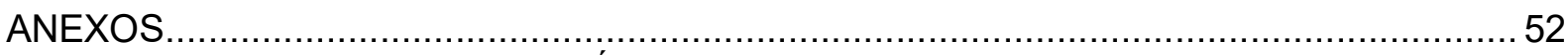

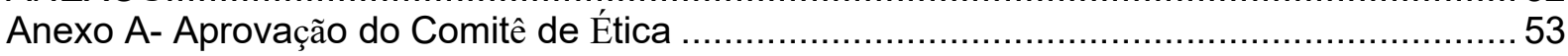




\section{1-INTRODUÇÃ̃O}

Saúde Global pode ser definida como uma área de pesquisa, estudo e atuação profissional que prioriza a melhoria da saúde de todos, mundialmente, com ênfase em problemas de saúde internacional, determinantes sociais e suas soluções, sendo essas ações realizadas envolvendo diversas áreas do conhecimento (sendo da saúde ou não) (KOPLAN ET AL, 2009; WILSON et al.,2016; BURTON et al, 2021).

Os temas de interesse para a saúde global são problemáticas de alta magnitude no panorama mundial, com tendências e padrões recorrentes. Poucos eventos nas últimas décadas afetaram tanto este cenário como o advento do HIV/aids, uma vez que este fenômeno tem proporções globais, mostrando-se dinâmico e instável, intimamente relacionado a fatores como o comportamento individual, coletivo, com tendências temporais e políticas (BRITO, 2001, BEKKER et al, 2018).

Sua importância no cenário global pode ser percebida até mesmo na sua classificação de pandemia, visto que infecção pelo vírus não é limitada por barreiras geopolíticas, no entanto apresenta características e padrões epidemiológicos que variam de acordo com a região, tornando-se dinâmica e de complexo controle (KAGOTHO, SSEWAMALA; 2012; ORTBLAD et al, 2013). A compreensão dessas diferenças e especificidades contribui para a vigilância global da epidemia e a criação de intervenções cada vez mais especificas, efícazes e inovadoras.

No Brasil, existem aproximadamente 760.955 pessoas vivendo com HIV vinculadas ao SUS; desde os primeiros dados sobre a aids na década de 1980, até junho de 2021, foram registrados 1.011.617 casos de aids e 281.156 óbitos (Indicadores HIV/AIDS - DCC). Ao analisarmos estes dados no contexto geopolítico da América Latina pode-se perceber como há um crescimento em novos casos no Brasil, ao contrário da região, que apresenta dados de estabilidade ou remissião (LUZ; VELOSO; GRINSZTEJN, 2019), evidenciando um descontrole da infecção no país.

Ao analisar a situação da pandemia globalmente é perceptível não tratar- se mais de uma doença restrita a grupos populacionais, mas sim, uma condição que pode afetar, quase indiscriminadamente, a todos. No entanto, apesar dessa heterogeneidade, existem grupos chaves para o controle da infecção dentro do contexto global, grupos de maior vulnerabidade vulnerabilidade na qual se inserem os homens que fazem sexo com homens (HSH) (MAYER et al, 2021; CASTRO et al, 2016; UNAIDS; 2020).

Em 2014, em uma ação conjunta para combater a aids como ameaça à saúde pública até 2030, o UNAIDS lançou as metas 90-90-90. Os objetivos são de que, até 2020, 90\% de 
todas as pessoas vivendo com HIV conheçam seu estado sorológico positivo para o vírus, $90 \%$ de todas essas pessoas diagnosticadas com HIV tenham acesso ao tratamento antirretroviral, e que $90 \%$ de todas as pessoas em tratamento tenham carga viral indetectável (LEVI et al, 2016).

Análise sobre a completude da meta, leva a estimar-se que $81 \%$ das pessoas que vivem com HIV sabiam seu status sorológico em 2019 e mais de dois terços (67\%) de todas as pessoas que vivem com HIV faziam terapia antirretroviral. Apesar disso, poucos países alcançaram as metas de 90-90-90 até o final de 2020. Em virtude disso, mais de um quarto (28\%) dos países, menos da metade de todas as pessoas que vivem com HIV reprimiram cargas virais em 2019 (UNAIDS, 2020). A meta, ainda que não cumprida em sua totalidade, foi fundamental para guiar ações, pesquisas e políticas em sua vigência, sendo atualmente substituída por novas diretrizes, ainda mais complexas, visando a eliminação de desigualdades que afetem o acesso ao serviço de saúde.

Visando atender as demandas da meta 90-90-90, percebemos como uma estratégia, ainda que subutilizada encontra-se no centro dessas demandas: a Profilaxia Pós-Exposição ao HIV (PEP). Ao seguir seu protocolo os usuários são levados a testagem, podendo ser encaminhados à profilaxia, ao tratamento (caso seja necessário) e até mesmo ofertados à PrEP, sendo assim uma ferramenta multipotente para a interrupção da cadeia de transmissão do HIV.

O principal desafio para a consolidação da PEP como uma das principais medidas preventivas contra o HIV é a necessidade de um período específico para início do tratamento, tido como "ótimo" de 2 horas, e aceitável até 72 horas. Por isso, essa situação é considerada como de emergência no Sistema Único de Saúde (SUS) (BRASIL, 2018).

A implantação da PEP no SUS como parte da cascata de cuidado para a prevenção da infecção pelo HIV aconteceu em 2015, com a publicação do Protocolo Clínico e Diretrizes Terapêuticas: Profilaxia Antirretroviral Pós-Exposição de Risco para Infecção pelo HIV. No entanto, desde 1990 essa tecnologia já é utilizada de forma restrita, principalmente em caso de acidentes com materiais contaminados ou potencialmente contaminados. Posteriormente, foi gradualmente sendo expandida para casos de violência sexual (1998) e depois exposições sexuais, independente do contexto (2011) (BRASIL, 2018).

A despeito disso, a falta de conhecimento a respeito da PEP, por usuários e profissionais, ainda é uma das grandes barreiras para seu uso. Populações-chave para o controle da infecção são os principais usuários em potencial para essa estratégia, mas para isso precisam de conhecimento e habilidade para navegar o serviço de saúde. Pesquisa recente aponta que casais soro-discordantes em tratamento desconhecem a opção de aderir a PEP 
como opção de prevenção (SAID; SEIDL, 2015) e homens que fazem sexo com homens (HSH) não identificam situações de risco para a exposição ao vírus (DOLEZAL et al, 2015).

A literatura aponta que, ainda que fundamentais, os dados sobre o uso de PEP são insuficientes, coletados de forma retrospectiva e não sistemática (WHITLOCK et al., 2016). O uso de m-Health pode apresentar uma oportunidade para melhorar a identificação e gestão de usuários dessa forma de prevenção.

\subsection{Referencial Temático}

\subsubsection{Estratégias de prevenção a infecção pelo HIV}

Desde a implementação da Terapia Antirretroviral de alta potência (TAARV), há cerca de duas décadas, os avanços no tratamento e qualidade de vida de pessoas que vivem com HIV são constantes e cada vez maiores.

Recentemente, resultados de coortes que acompanharam Pessoas Vivendo com HIV/aids (PVHA) desde o início do seu tratamento com a TAARV (na década de 90) apontam que a expectativa de vida dessas pessoas está muito semelhante àquelas sem o vírus (TRICKEY et al, 2017).

Apesar desses grandes avanços em seu tratamento a prevenção do HIV ainda está longe do esperado, relatórios da UNAIDS (2020) apontam para o crescimento de casos diagnosticados principalmente entre populações chaves para o controle da infecção, principalmente: homens que fazem sexo com homens (HSH) e mulheres transexuais. Este cenário é ainda mais preocupante em países da América Latina, com destaque para o Brasil, sendo o único que ainda apresentou aumento no número de novas infecções na última década, em torno de $11 \%$.

É nesse contexto que se fazem necessárias medidas eficazes e inovadoras de prevenção ao HIV. Destaque aqui para o termo "inovador", uma vez que as políticas públicas de prevenção ao HIV e outras Infecções Sexualmente Transmissíveis (IST) ainda são antiquadas, com um enfoque essencialmente heterossexista e no uso do preservativo masculino.

A testagem é uma medida preventiva eficaz, mas ainda muito subutilizada, sendo o ponto de partida de todas as outras formas, pois é a partir do conhecimento de seu status sorológico que os indivíduos podem tomar decisões condizentes para sua prevenção e de terceiros.

Esta situação coloca o uso da PEP ainda mais em evidência, por ser a tecnologia mais recente disponível no país. O Ministério da Saúde, pensando nisso, desenvolveu um app que 
reúne uma série de informações sobre essa estratégia, mas ainda é pouco conhecido e não possui vínculo com os serviços existentes (BRASIL, 2018).

\subsubsection{Tecnologias em saúde}

A produção de tecnologia na area da saúde, sejam elas duras ou leves, vêm crescendo notoriamente, tanto em um cenário nacional como internacional. Isso parece ser uma evolução lógica da ciência que, cumprindo seu objetivo máximo, busca diminuir as mazelas da sociedade. Uma vez que identificados problemas passa-se a buscar explicá-los e resolvê-los.

Baseado nisto, esta área vem se beneficiando dos avanços tecnológicos ao longo dos anos. Reflexo disto é a utilização de ferramentas computacionais na área da saúde principalmente para fins de diagnóstico, tratamento, monitoramento remoto, e apoio à tomada de decisão (FREE et al, 2010).

Tecnologias moveis, se destacam ainda mais pela precisão e agilidade de seus recursos e interfaces, tornando o uso de sistemas móveis para a saúde (m-Health) um campo crescente com vários sistemas participativos aplicáveis a área de saúde pública (KAY; SANTOS; TAKANE, 2011).

\subsection{3. eHealth}

O cuidado integral é um dos objetivos centrais em praticamente todas as areas da saúde, e busca um atendimento holístico, personalizado e que promova a saúde de seu usuário.

De forma semelhante, usuários de tecnologias (aqui focando nos smartphones) utilizam-se de suas ferramentas para criar uma experiência personalizada, que supra da melhor forma as suas necessidades e, justamente por isso, em constante mudança e aprimoramento. Um elemento central nessa personalização são os aplicativos, que permitem desempenhar funções das mais diversas e especificas.

Portanto, utilizar-se dessas plataformas para intervenções de saúde possui um grande potencial de êxito, adesão e inovação. Inicialmente os aplicativos utilizados em mHealth eram destinados ao profissional, como uma forma de suporte em questões de diagnóstico, abordagens terapêuticas e prescrições de medicamentos utilizando sensores específicos para tais fins. Mais recentemente as novas aplicações desenvolvidas passam a ser mais voltadas ao usuário/paciente, capazes de diminuir sua distância com a equipe de saúde.

A exemplo disso, existe no Brasil o desenvolvimento de algumas aplicações móveis voltadas para o monitoramento do paciente, seu tratamento, aprendizado e para a melhoria em 
seu atendimento (KAY; SANTOS; TAKANE, 2011). Para isso as aplicações podem coletar dados através de campos para preenchimento pelo usuário, ou a coleta de dados por meio de sensores que são conectados e alimentam o celular com informações necessárias e específicas, e enviá-los diretamente à equipe de saúde.

Para que seu desenvolvimento e características correspondam a seus objetivos, geralmente esses aplicativos são concebidos por profissionais de saúde e desenvolvidos por profissionais das ciências da computação. No entanto, ainda não existe uma regulamentação para este desenvolvimento; o que existe, de fato, é uma classificação feita pela Organização Mundial da Saúde (OMS) (IWAYA et al, 2013, MECHAEL et al, 2010) com as principais iniciativas de E-health.

São elas:

a) Centros telefônicos (call center) em atendimento médico: Sistema de prestação de serviços de triagem e conselhos de saúde por profissionais capacitados, utilizando telefonia;

b) Serviços de emergência por telefone sem taxas/gratuitos: Sistemas frequentemente utilizados para acesso rápido a serviços/profissionais de saúde ou pessoal capacitado para fornecer orientação durante emergências médicas. É o equivalente no Brasil ao 192 do SAMU;

c) Aplicações de Emergências voltadas a saúde pública: é tido como o uso de dispositivos móveis para responder a emergências ou desastres como surtos de doenças;

d) Serviços de Telemedicina móvel: É entendido como o uso de funções comuns aos dispositivos móveis em situações de saúde, como comunicação entre profissionais de saúde para consulta, auxílio em dúvidas de diagnostico, entre outras. É útil em situações em que há escassez de recursos humanos.

e) Lembretes por telefone: serviços baseados no envio/troca de mensagens de voz ou SMS (Short Message Service) enviadas aos pacientes, para agendar consultas, entregar resultados de tratamento, lembrar de buscar exames, tomar medicamentos ou outros.

f) Mobilização comunitária para a promoção da saúde: Uso de mensagens de texto para a promoção da saúde em grandes grupos-alvo de campanhas de saúde, comumente utilizado em campanhas para doenças sexualmente transmissíveis como HIV/aids.

g) Cumprimento do tratamento: pode ser descrito como a entrega de mensagens de lembrete, por voz ou SMS, com o objetivo de melhorar a adesão ao tratamento, erradicação da doença e superar desafios como a resistência à tomada dos medicamentos necessários. É comumente aplicado para apoiar pacientes que sofrem de doenças crônicas, como diabetes, HIV / aids, e TB.

h) Sistemas de Registros de Pacientes: utilização de dispositivos móveis para apoiar o tratamento de pacientes. Esse tipo de aplicação voltado a á saúde permite o acesso a registros médicos 
eletrônicos em um ponto distante daquele onde o serviço está sendo prestado, por meio de tecnologias móveis.

i) Sistemas de iniciativas para informação: compreende serviços que fornecem acesso a publicações de ciências da saúde ou bases de dados no ponto de atendimento, por meio de dispositivos portáteis.

j) Aplicações para monitoramento do paciente: é o uso de tecnologia para gerenciar, monitorar e tratar um paciente com alguma doença à distância. É especialmente utilizado em doenças crônicas como diabetes. A troca de informações necessárias e importantes pode reduzir a necessidade de visitas as instituições de saúde e informar as equipes a necessidade de atendimento de emergência.

k) Pesquisas em saúde: é o uso de dispositivos móveis para coleta de dados relacionados à saúde.

1) Sistema de vigilância: utilização de dispositivos móveis para alimentação e transmissão de dados que podem ser utilizados por programas de vigilância para rastrear doenças.

m) Sensibilização: inclui o uso de produtos de informação de saúde, jogos ou programas de questionário para educar as pessoas sobre temas de saúde relevantes, como HIV/aids.

n) Sistemas de suporte à decisão: definidos como algoritmos que auxiliam provedores de saúde em diagnósticos clínicos no atendimento ou gerencia de saúde para tomar ações com base em dados coletados de pesquisas de saúde.

As possibilidades de conexão trazidas pelos smartphones mudaram de forma simples, mas definitiva, as percepções sobre o que é "ficar conectado (online)". A independência que a mobilidade dos smartphones traz coloca o uso de computadores (dekstops) em uma posição de obsolescência, visto os primeiros funcionam como um computador portátil, que também possui tela sensível ao toque (touch screen) e tamanho reduzido, facilitando sua locomoção.

$\mathrm{O}$ acúmulo de funções pelos smartphones é outra vantagem que os coloca como destaque entre novas tecnologias, cabendo mencionar, principalmente a capacidade em realizar ligações, enviar e receber mensagens de texto, baixar aplicativos, o uso de GPS, acesso a internet e a possibilidade de que todas essas funções interajam (multitarefas) (ESTRIN; SIM, 2010).

\subsection{4. eHealth no Brasil}

No Brasil, o Instituto Brasileiro de Geografia e Estatística (IBGE), por meio da Pesquisa Nacional Por Amostra de Domicílios (Pnad), estima que ao menos 80,4\% das famílias brasileiras já utilizam o smartphone como principal meio de acesso à internet, em comparação com o uso de computadores, notebooks e tablets (CETIC, 2015). Essa cobertura tecnológica coloca o Brasil como um cenário propício a futuras intervenções de eHealth, com 
as ressalvas necessárias de se levar em consideração as diferenças entre centros urbanas e áreas rurais e periféricas.

Essa "cobertura tecnológica" faz um interessante paralelo com o alcance do Sistema Único de Saúde (SUS), que atualmente abrange cerca de $80 \%$ dos brasileiros e oferece acesso universal e gratuito à saúde. Garantir esse acesso a diversas formas tratamento, prevenção e promoção de saúde tem-se mostrado o grande desafio ao SUS, que se esforça para acompanhar sua demanda tanto em número de usuários como em necessidades especificas (GUIMARÃES, 2014, MASSUDA et al, 2018).

\subsubsection{COVID-19}

As desigualdades sociais que afetam as minorias são sistematicamente relatadas nos mais diversos cenários. A pandemia COVID-19, no entanto, escalou esta situação para níveis nunca vistos antes e das formas mais variadas.

Os sistemas de saúde costumam estar mal equipados para combater essas desigualdades, tanto por questões estruturais, que moldam suas políticas públicas e padrões, quanto por seus profissionais, que reproduzem comportamentos violentos e perpetuam as disparidades de saúde para as populações marginalizadas (PHILLIPS II et al., 2020).

Em 2020, a pandemia por COVID-19 atingiu todo o mundo causando impacto em praticamente todos os sentidos da vida possível (SOUSA et al., 2020). A extensão do surto levou a Organização Mundial da Saúde (OMS) a declarar o surto de COVID-19 como uma emergência global em 30 de janeiro de 2020 (WU et al, 2020). Em resposta às diretrizes de isolamento social e medidas não-farmacológicas de mitigação da pandemia, os governos impuseram o fechamento das fronteiras, restrições de viagens e quarentena em países que constituem as maiores economias do mundo, contribuindo para uma crise econômica iminente e recessão.

O cenário de instabilidade política e sanitária potencializa os efeitos da pandemia, principalmente entre os grupos mais vulneráveis, como as Pessoas Vivendo com HIV (PVHIV). A sobrecarga do sistema de saúde pode prejudicar diretamente os sistemas de saúde e a meta 90-90-90 do UNAIDS (2020), conceitos ainda mais amplos em saúde e justiça social, como equidade.

A OMS recomenda que a equidade deve ser um fator motivador para a cobertura universal de saúde de uma determinada nação, que também estabelece as bases para quaisquer debates sobre políticas públicas (HAJIZADEH; EDMONDS, 2020), principalmente por meio de financiamento justo do sistema de saúde e acesso justo aos serviços de saúde. Assim, a equidade e a justiça na saúde têm sido tradicionalmente vistas, estudadas e debatidas a partir 
de duas perspectivas: equidade no financiamento da saúde e na utilização dos serviços de saúde (ETIENNE; ASAMOA-BAAH; EVANS, 2010).

É consenso que esta pandemia pode sobrecarregar os sistemas de saúde (LEGIDOQUIGLEY et al., 2020). No entanto, tais sistemas diferem em todo o mundo, de modo que as respostas baseadas em evidências para aliviar o fardo podem não ser eficazes para todos os países. Ainda assim, respostas bem-sucedidas, como garantir um fornecimento rápido de recursos para os ambientes de saúde e, para os profissionais de saúde, são primordiais (TANNE et al., 2020), pois contribuem para prevenir a escassez de pessoal dentro do ambiente de saúde.

A pandemia COVID-19 causou um desafio sem precedentes para os sistemas de saúde em todo o mundo. No Brasil, a falta de medidas públicas aumenta o risco para os trabalhadores da saúde, colocando-os em uma das maiores vulnerabilidades dos sistemas de saúde em todo o mundo. Considerando que a maioria dos profissionais de saúde não consegue trabalhar remotamente, estratégias são imperativas, incluindo a implantação precoce de testes virais para profissionais de saúde assintomáticos e/ou de linha de frente. Os altos custos de saúde, a escassez de equipamentos de proteção, incluindo máscaras N95 e o baixo número de leitos de UTI e ventiladores, acabaram por expor fragilidades na prestação de cuidados ao paciente (NICOLA et al., 2020).

Esses efeitos também são sentidos nos nívieis de atenção primária e secundária, que se tornam ambientes inseguros pela concentração de pessoas, falta de equipamentos de proteção individual e até mesmo pelas exposições acumuladas durante o trajeto até esses serviços (principalmente considerando transportes públicos e coletivos). Em especial serviços de prevenção e promoção da saúde são recontextualizados pelos usuários dentro das suas prioridades de saúde, em uma compensação de risco atualizada pela pandemia de COVID-19, o que pode trazer efeitos deletérios a um nível populacional no futuro, principalmente com novos casos de doenças evitáveis como o HIV.

\section{OBJETIVOS}

\subsection{Objetivo Geral}

- Explorar o acesso aos serviços de saúde que ofertam a Profilaxia Pós exposição ao HIV e as tecnologias disponíveis para auxiliá-lo.

\subsection{Objetivos específicos}

- Identificar necessidades e dificuldades de usuários e profissionais para o acesso e encaminhamento de pessoas expostas sexualmente ao HIV à PEP. 
- Identificar tecnologias eletrônicas móveis disponíveis para a identificação, triagem e encaminhamento de pessoas expostas sexualmente ao HIV para serviços de saúde;

\section{METODOLOGIA}

\subsection{Design do estudo}

Trata-se de um estudo multi-método (DRIESSNACK; SOUSA; MENDES, 2007) desenvolvido em etapas concorrentes. A pesquisa foi constituída de duas etapas: uma online e a outra presencial, conforme descrito à seguir:

\subsubsection{Etapa 1: Estudo exploratório e descritivo com abordagem qualitativa}

Para a identificação dessas necessidades foram realizadas análises qualitativas baseadas na teoria do Discurso do Sujeito Coletivo.

Os dados foram coletados por meio de entrevistas em profundidade com profissionais de saúde que compunham as equipes multiprofissionais dos Serviços de Assistência Especializada (SAE) e com usuárias do serviço que já se utilizaram da PEP em algum momento, selecionados segundo diferentes critérios de inclusão: entre os profissionais de saúde, buscou-se a inclusão de pelo menos um profissional de cada categoria das cinco equipes integrantes, respeitados o interesse e a disponibilidade para participar do estudo. Entre os usuários, foram convidados aqueles que, em algum momento já se utilizaram do serviço para ter acesso à PEP. As entrevistas foram realizadas por pesquisadores treinados, individualmente, em uma sala de atendimento do serviço de saúde e, posteriormente, gravadas, transcritas e submetidas à análise do discurso.

\subsubsection{Etapa 2: Estudo de Prospecção de Tecnologias}

Realizou-se uma prospecção tecnológica, com o intuito de buscar informação sobre o processo de gestão tecnológica e, assim, mapear o desenvolvimento de projetos e de futuras tecnologias que possam afetar as metas estabelecidas.

A prospecção tecnológica é um meio sistemático de identificar desenvolvimentos científicos e tecnológicos com potencial de influenciar de forma significativa uma indústria, a economia ou a sociedade como um todo, bem como permite demarcar o que poderá ser um êxito em temos de inovação tecnológica (SANTOS et al, 2010).

Sobre o tema, Santos e colaboradores (2010) afirmam que os estudos de Prospecção Tecnológica são fundamentais para orientar esforços empreendidos para o desenvolvimento de tecnologias. Atualmente estes estudos se constituem em componentes fundamentais para 
ampliar a capacidade de antecipação e estimular a organização dos sistemas de inovação, transcendendo o âmbito empresarial, para o meio acadêmico.

Esta etapa do estudo foi feita por meio de buscas sistematizadas e simultâneas em três bases de dados (Web of Science, PubMed e CINAHL), utilizando descritores controlados e padronizados de acordo com cada base, três bases de patentes (European Patent Office EPO; Escritório Americano de Marcas e Patentes -USPTO; e Instituto Nacional de Propriedade Intelectual - INPI). Além disso, foi utilizado o "Google play" (baixador de aplicativos do Google) e App store (baixador de aplicativos da Apple), por meio de descritores controlados associados aos operadores boleanos $A N D$ e $O R$.

\subsection{Aspectos Éticos}

Foram atendidas as recomendações para o desenvolvimento de pesquisas com seres humanos, sendo o projeto aprovado pelo Comitê de Ética da Escola de Enfermagem de Ribeirão Preto (CAAE: 08198819.2.0000.5393) (parecer nº 3.280.490). 


\section{RESULTADOS}

4.1. Objetivo 1: Identificar necessidades e dificuldades de usuários e profissionais para o acesso e encaminhamento de pessoas expostas sexualmente ao HIV à PEP.

Publicado no periódico: Acta Paulista de Enfermagem 


\section{APE-2021-0076.R2_Artigo Original}

\section{Barreiras de acesso à profilaxia pós-exposição ao HIV: estudo de caso}

Artur Acelino Francisco Luz Queiroz (https://orcid.org/0000-0002-6350-1908) 1,2 $^{1,2}$ Isabel Amélia Costa Mendes (https://orcid.org/0000-0002-0704-4319) ${ }^{1}$

Sonia Dias (https://orcid.org/0000-0001-5085-0685) ${ }^{2}$

Como citar:

Queiroz AA, Mendes IA, Dias S. Barreiras de acesso à profilaxia pós-exposição ao HIV: estudo de caso. Acta Paul Enferm. 2022:exxxx.

\section{Submetido}

29 de Março de 2021

\section{Aceito}

21 de Junho de 2021

${ }^{1}$ Escola de Enfermagem de Ribeirão Preto, Universidade de São Paulo, Ribeirão Preto, SP, Brasil.

Escola Nacional de Saúde Pública, Universidade Nova de Lisboa, Lisboa, Portugal.

Conflitos de interesse: nada a declarar.

\section{Autor correspondente}

Isabel Amélia Costa Mendes

Avenida dos Bandeirantes, 3900, 14040-902, Campus Universitário, Monte Alegre, Ribeirão Preto, SP, Brasil.

Email: iamendes@usp.br

\section{Resumo}

Objetivo: Explorar as barreiras de acesso à Profilaxia Pós Exposição ao HIV percebidas por usuários e profissionais. Métodos: Pesquisa exploratória com abordagem qualitativa. Os participantes da pesquisa foram profissionais médicos e enfermeiros envolvidos no protocolo da profilaxia em Centros de Referência e usuários da prevenção, totalizando 10 participantes, amostragem definida por saturação de dados. As entrevistas gravadas foram transcritas e posteriormente processadas pela Classificação Hierárquica Descendente e por análise de Similitude.

Resultados: Foram obtidas cinco classes: Informação; Centralização de acesso; Fluxo de atendimento; Relações interpessoais nos serviços de saúde e Dificuldades e Barreiras. Existem diversos fatores dificultadores no acesso à prevenção, que perpassam conhecimento, acolhimento e divulgação de informações. Diante do advento da Pandemia de COVID-19 muitos desses problemas se agravam e aumentam a vulnerabilidade de possiveis utilizadores da profilaxia.

Conclusão: $O$ acesso à profilaxia pós-exposição ao HIV encontra desafios e barreiras, que vão desde o desconhecimento sobre a profilaxia, o que impossibilita sua busca, à centralização dos serviços de saúde e estigmas que permeiam as estruturas dos serviços de saúde.

\section{Introdução}


Em 2014, em uma ação conjunta para combater a aids como ameaça à saúde pública até 2030, o Programa Conjunto das Nações Unidas sobre HIV/Aids (UNAIDS) lançou as metas 90-90-90, de modo que, até 2020, 90\% das pessoas vivendo com o Vírus da Imunodeficiência Humana (do inglês HIV) conheçam seu estado sorológico positivo para o vírus, $90 \%$ dos diagnosticados com HIV tenham acesso ao tratamento antirretroviral, e que $90 \%$ das pessoas em tratamento tenham carga viral indetectável. ${ }^{(1)}$

Ao analisar a completude da meta, ${ }^{(2)}$ percebemos na Profilaxia Pós-Exposição ao HIV (PEP) um ponto de encontro desses indicadores: ao atenderem o protocolo da PEP os usuários (muitos deles de alta vulnerabilidade) são aderidos ao sistema de saúde e encaminhados para tratamento, se necessário. (3)

A implantação da PEP no Sistema Único de Saúde (SUS) como parte da cascata de cuidado para a prevenção da infecção pelo HIV aconteceu em 2015. No entanto, desde 1990 essa tecnologia já é utilizada de forma pontual, principalmente em caso de acidentes com materiais contaminados ou potencialmente contaminados. Posteriormente, foi gradualmente sendo expandida para casos de violência sexual (1998) e depois para qualquer tipo de exposição sexual (2011).(3)

Apesar disso, ainda é registrado uma falta de conhecimento a respeito da PEP pela população e profissionais. Populações vulneráveis para o controle da infecção são aqueles potencialmente enfocados nessa estratégia, mas para isso devem ser devidamente instruídos pelo serviço de saúde. Pesquisas recentes apontam que casais soro-discordantes em tratamento desconhecem a opção de aderir a PEP como opção de prevenção ${ }^{(4)}$ e homens que fazem sexo com homens (HSH) não identificam situações de risco para a exposição ao vírus. ${ }^{(5)}$

Desse modo, esse estudo tem por objetivo explorar as barreiras de acesso à Profilaxia Pós Exposição ao HIV percebidas por usuários e profissionais.

\section{Métodos}

Pesquisa exploratória, de abordagem qualitativa fundamentada no método do Discurso do Sujeito Coletivo, onde as falas foram organizadas e tabuladas por meio de expressões-chave que permitiram a identificação das ideias centrais, para que o pensamento coletivo fosse apreendido e agrupado em categorias. ${ }^{(6)}$

O estudo foi realizado com profissionais da Unidade Básica de Saúde que desenvolviam atividades junto ao e o Centro de Testagem e Aconselhamento (CTA) ou Unidades de Pronto Atendimento (UPA) com atuação há pelo menos 1 ano. Excluíram-se profissionais que estavam de licença, férias e que não atuavam com o protocolo da PEP.

Entre os usuários, foram convidados os que, em algum momento, em algum momento, já utilizaram o serviço para acessar a PEP, estivessem usando a profilaxia nesse período ou no 
seguimento posterior. Foram excluídas pessoas privadas de liberdades, devido às diferenças intrínsecas de atendimento dentro do sistema prisional.

As entrevistas ocorreram, após assinatura do Termo de Consentimento Livre e Esclarecido, entre junho e agosto de 2019, nos dois serviços que disponibilizam a PEP em Ribeirão Preto (SP): a UPA e o CTA em sala reservada da instituição, guiada por um roteiro semiestruturado, composto de três questões abertas, que abordavam: a experiência prévia com a PEP, as dificuldades percebidas para seu acesso e quais seriam as formas de diminuir ou eliminar essas dificuldades. A amostra foi composta por 6 usuários e 4 profissionais. As entrevistas tiveram duração média de 30 minutos, foram gravadas e transcritas na íntegra para análise, os participantes foram entrevistados até atingir a saturação dos dados.

Para processamento de dados, empregou-se a técnica de análise do tipo lexical, com o auxílio do software IRaMuTeQ.(7,8) Para a análise textual, definiu-se o método da Classificação Hierárquica Descendente (CHD), em que os textos são classificados em função de seus respectivos vocábulos e o conjunto deles se divide pela frequência das formas reduzidas. ${ }^{(9)}$ Posteriormente, procedeu-se a organização das expressões-chave retiradas dos discursos dos entrevistados e identificação das ideias centrais as quais complementaram os achados da CHD e permitiram a delimitação dos depoimentos em classes definitivas. ${ }^{(8)}$

Complementarmente a isso, foi utilizada a análise de similitude, representando graficamente a estrutura de um conjunto de elementos com os quais a pesquisa linguística se relaciona, distinguindo as partes comuns das especificidades das variáveis codificadas. ${ }^{(10)}$

Foram atendidas as recomendações para o desenvolvimento de pesquisas com seres humanos, sendo o projeto aprovado pelo Comitê de Ética da Escola de Enfermagem de Ribeirão Preto (CAAE: 08198819.2.0000.5393) (parecer $n$ 우 3.280.490).

\section{Resultados}

O IRaMuTeQ reconheceu a separação do corpus em 791 unidades de texto elementares, a partir de 110 segmentos de textos. Foram registradas 3794 ocorrências, com aproveitamento de

\begin{tabular}{l}
\hline \multicolumn{2}{|c|}{ Barreiras de acesso à Profilaxia Pós Exposição ao HIV } \\
\cline { 1 - 1 } \\
\cline { 1 - 1 }
\end{tabular}


$60.91 \%$ do corpus total, valor que permite sua avaliação, mas indica um baixo nível de conteúdo por parte dos entrevistados, que mesmo inseridos nesta realidade tinham pouca propriedade sobre a problemática (Figura 1).

Figura 1. Dendrograma

\section{Classe 1: Informação}

Esta classe, a primeira a ser formada, demonstra o início do caminho dos usuários à PEP, retratando seus primeiros contatos com a prevenção e como tiveram conhecimento sobre ela. $\mathrm{O}$ desconhecimento afeta diretamente o acesso, fazendo com que os usuários busquem serviços que não prestam o atendimento. A busca pela PEP, em diferentes serviços, faz com que muitos participantes percam o tempo ótimo de acesso (2h) ou até mesmo desistam de buscá-la. Durante os relatos é uma constante que a fonte principal de informação não vem do Serviço de Saúde ou de profissionais, mas de seus pares que já se utilizaram da PEP, o que não exime os entrevistados de uma situação de tentativa e erro, ao buscar maiores informações, serviços e apoio do serviço de saúde.

\section{Classe 2: Centralização de acesso}

Esta classe comportou-se como um aprofundamento de uma das barreiras elencadas: a centralização do acesso à PEP. Ainda que disponível em dois tipos de serviços, usuários e profissionais apontam a dificuldade no dia-a-dia desse acesso. A UPA, por sua estrutura e escopo de atendimento, se mostra constantemente superlotada, com longas esperas e pouca privacidade, de forma que muitos participantes escolhem (ou são indicados a) procurar o serviço especializado. Essa situação coloca em risco até mesmo a eficácia da PEP, uma vez que o Centro Especializado funciona em horário comercial e a busca pela UPA fora dessa janela de tempo pode forçar os indivíduos para além das 72 horas de funcionalidade da PEP.

\section{Classe 3: Fluxo de atendimento}

Os conteúdos apreendidos nessa classe aparecem como transversais aos das classes anteriores, reunindo os entraves do serviço ao atender aqueles pacientes que conseguem informação (Classe 1) sobre os serviços e Acesso ao mesmo (Classe 2). A construção da experiência de acesso à profilaxia, então, é um processo árduo e que em muitos momentos estimula à sua desistência.

\section{Classe 4: Relações interpessoais nos serviços de saúde}


Esta classe encontra-se intimamente relacionada à classe 5, e revela um aspecto particular dos achados: a forma como as relações interperssoais permeiam a navegação pelo sistema de saúde, até alcançar o acesso ao serviço desejado. No entanto, elas podem até mesmo sobrepujar os Protocolos Clínicos, uma vez que mesmo seguindo as recomendações, os usuários podem se deparar com situações vexatorias, de descaso ou violência, criando um ambiente hostil que dificulta o acesso de novos usuários e a adesão de atuais. Em uma terceira esfera, percebe-se o receio do olhar do outro sobre sua decisão de frequentar o serviço de saúde especializado. 0 estigma sobre o HIV é ainda uma das grandes barreiras para toda e qualquer forma de prevenção, por isso tornar esses ambientes acolhedores vai além de tornar ambientes agradáveis, mas verdadeiramente transformá-los como uma estratégia de prevenção.

\section{Classe 5: Dificuldades e Barreiras}

Esta classe se forma a partir de uma bifurcação da anterior, revelando como aspectos básicos (informação) influenciam toda a experiência de acesso a PEP e apresenta-se como sua principal dificuldade. Os profissionais enxergam como detalhes estruturais acabam por afastar as pessoas. Ao buscar evitar o estigma de ir a um centro de tratamento para doenças infecciosas, os indivíduos se dirigem a Unidade de Pronto atendimento e não conseguem acesso, sendo encaminhados para os CTAs. Esse percurso, mediado pelo estigma ao HIV e aos seus serviços, torna o processo mais demorado e põe em risco a eficácia da PEP. Ao serem questionados sobre como esse processo poderia ser melhorado, usuários e profissionais convergiram ao apontar o auxílio de tecnologias para disseminar informação e mediar o primeiro acesso ao serviço de saúde, focando na agilidade da troca de informação e privacidade. 


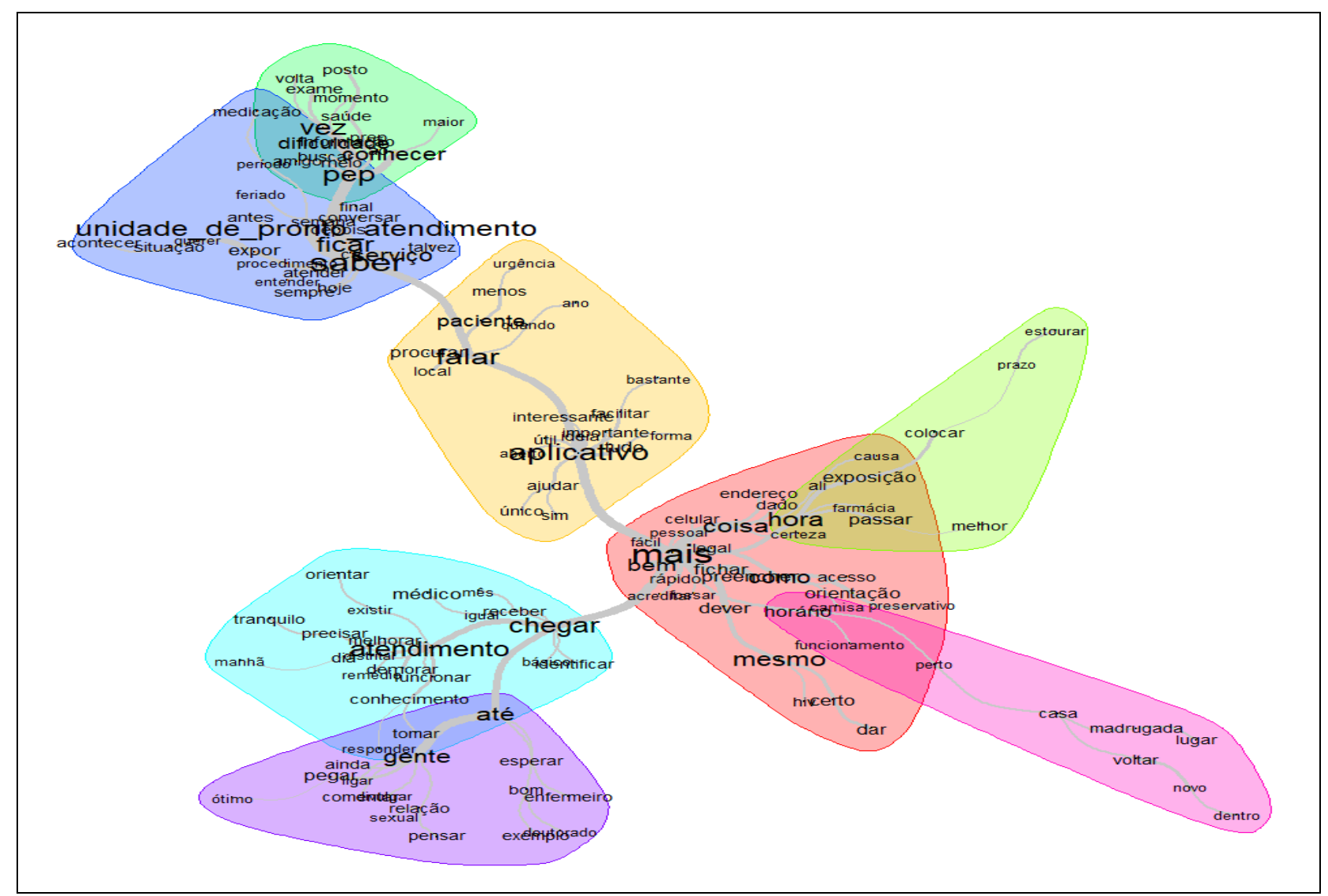

Figura 1. Análise de similitude

$\mathrm{Na}$ análise de similitude (Figura 2) conseguimos perceber núcleos de ideias formados a partir das experiências compartilhadas. O primeiro desses núcleos, no quadrante superior esquerdo, aponta como primeira barreira de acesso a dificuldade em conhecer a PEP, e a partir dela vemos seus desdobramentos. A Unidade de Pronto Atendimento aparece nos relatos como uma alternativa para horários fora do ordinário (termo: período e feriado) não como uma solução para a busca, mas como uma etapa do processo, em que as pessoas são informadas (termo: saber) onde buscar atendimento e a PEP (termo: medicação).

A partir daí o corpus converge para um ponto que trata de dois assuntos: a preocupação de a PEP ser uma situação de urgência e como estratégias tecnológicas poderiam ajudar a solucionar as dificuldades apontadas (termo: aplicativo).

Procurando superar essas dificuldades, os participantes apontam rotas de melhorias: aumentar a agilidade e assim diminuir o tempo de acesso a PEP, como destacado pelos termos: mais, rápido, hora e prazo. Informar os locais de acesso à PEP, priorizando aqueles mais próximos às pessoas, tornando seu acesso mais fácil (termos: local, perto e casa). Por fim, mesmo após chegar ao serviço de saúde o atendimento ainda representa uma barreira e reflete necessidade de orientação e acolhimento (termo: atendimento, médico e conversar).

\section{Discussão}


Existem diversas barreiras no acesso a PEP, percebidas por seus usuários e os profissionais, que perpassam conhecimento, acolhimento e divulgação da informação. Com a Pandemia de COVID19, muitos desses problemas se agravam e aumentam a vulnerabilidade de possíveis utilizadores.

Nos serviços de saúde, as considerações relativas à resiliência e capacidade adaptativa do ambiente construído são centrais para gerenciar os desafios de restrições de oferta, formas alternativas de prestação de serviços e continuidade ampla das operações. Anteriormente ligados aos impactos das mudanças climáticas, os conceitos são recentemente reatribuídos ao COVID19, o que revela a necessidade de maturidade nos setores de saúde para o desenvolvimento progressivo de práticas e estratégias essenciais associadas à resiliência organizacional.(11)

Em tempos de crise, reconheça-se que o futuro da pesquisa e da prática em vários domínios da resiliência e adaptação será definido pelas quantificações dos indicadores socioeconômicos e também pela qualificação da experiência humana em todas as suas capacidades de engenhosidade, empatia e responsabilidade moral. ${ }^{(12)}$ Assim como demonstrado em nossos resultados, ainda que a PEP possua protocolos claros e bem estabelecidos na rede de atenção, o fator humano se apresenta como uma barreira ainda maior.

Os profissionais e usuários concordam em que existe um distanciamento entre o serviço e a comunidade que visa atender, por vezes dependendo de conexões interpessoais para possibilitar esse acesso. A comunicação precisa e transparente dos serviços de saúde com a comunidade é essencial e desafiadora em emergências, porque determina a confiança do público nas autoridades em detrimento de rumores e desinformação.

A Pandemia de COVID-19 revela como problemas socio-estruturais são recorrentes nos serviços para HIV, devendo ser trabalhados continuamente para fortalecê-los e garantir um atendimento de qualidade que atenda as metas da UNAIDS.

Entre esses aspectos socio-estruturais destaca-se a homofobia estrutural que perpassa várias, senão todas, as instâncias do serviço. Esse fator não apenas afeta a vida de pessoas na comunidade LGBTQIA+, como fragiliza o serviço que falha em atender um dos seus públicos mais vulneráveis e, amplamente, contribui para uma sociedade desigual.

À luz das mudanças globais no financiamento de investimentos para as populações-chave mais afetadas pelo HIV (por exemplo, a ênfase do Fundo Global na orientação sexual e identidade de gênero em sua estratégia de investimento), a importância dos esforços paralelos para reduzir as barreiras ao acesso aos serviços relacionados ao HIV se mostra como uma tendência global com efeitos locais. Esforços direcionados para aliviar esta desigualdade no acesso a intervenções de prevenção do HIV baseadas em evidências para homens que fazem sexo com homens (HSH) são urgentemente necessários para conter com sucesso a epidemia de HIV nesta população. Por exemplo, campanhas de marketing social baseadas na comunidade direcionadas a redes sociais e estratégias de educação em saúde por pares têm se mostrado 
promissoras na expansão de testes de HIV, tratamento e conhecimento entre HSH mais jovens. ${ }^{(13)}$

As poucas intervenções baseadas em evidências que são específicas para esses homens mostram-se inadequadas, e aumentar as intervenções existentes de HIV por si só provavelmente será insuficiente, pois fatores sociais como a homofobia impedem a aceitação dos serviços de prevenção do HIV, especialmente entre este grupo. As disparidades na incidência e no acesso aos serviços de prevenção entre os HSH ainda persistirão, a menos que os serviços de prevenção sejam adaptados às necessidades específicas, as estratégias que promovem a resiliência sejam apoiadas e os esforços para reduzir as barreiras ao acesso sejam desenvolvidos e financiados. Os esforços e metas para erradicar o HIV só serão possiveis por meio de intervenções estruturais que abordam a homofobia e a discriminação - incluindo políticas que descriminalizam a homossexualidade - devem ser implementadas e priorizadas. ${ }^{(13)}$

A advocacia, visando a leis, políticas e práticas discriminatórias, também tem se mostrado eficaz para remover barreiras aos serviços de HIV, enquanto a evidência de garantir a aplicação da lei está aumentando. Existem evidências do impacto desses tipos de programas de direitos humanos para pessoas que vivem com HIV e populações-chave e vulneráveis ao HIV, variando desde a redução de comportamentos de risco até mesmo para uma incidência reduzida. Ademais, essas evidências apontam claramente para a necessidade de um melhor treinamento de profissionais de saúde reduzir o estigma e programas que promovam a educação legal e a defesa de direitos. ${ }^{(14)}$

Mas são poucos os programas de direitos humanos com financiamento adequado que abordam a discriminação operando em escala nacional. Frequentemente os programas de "estigma e discriminação" são pequenos ou enfatizam o estigma, mas ignoram leis, políticas e práticas discriminatórias. Contam com mensagens que exortam todos a agirem juntos para acabar com o estigma, enquanto ignoram mecanismos sistemáticos, como o judiciário, que podem identificar e responsabilizar aqueles que cometem discriminação. ${ }^{(15)}$ Individualizar 0 problema, apontando como culpados os pacientes que buscam a PEP por se exporem, ou os profissionais por atitudes homofóbicas, é uma simplificação do problema que não alcança suas raízes e, consequentemente, se afasta de uma solução.

Para realmente alcançar a discriminação zero em ambientes de saúde, os governos e os ambientes de saúde precisam reconhecer os problemas, como aqueles apontados nesta pesquisa, e mudá-los com ações concretas. Integrar assistentes jurídicos em unidades de saúde, criar ouvidorias, combinado com monitoramento independente e defensores da sociedade civil, começaria a tornar concreto que os serviços sejam verdadeiramente Zero Discriminação. Alcançar o "fim da AIDS" é também atender aos objetivos de desenvolvimento sustentável relacionados à saúde, e exige um compromisso com cuidados disponíveis, acessíveis, aceitáveis e de qualidade para todos. ${ }^{(16)}$ 
Nossos resultados, mesmo oriundos de uma realidade local, são reflexos de problemas maiores e estruturais, como mencionado anteriormente. A análise dessa realidade, e a exploração de como esta se conecta a diversas áreas de atuação, também permite refletir como a resposta a esses problemas não depende atitudes isoladas, mas de ações intersetoriais.

No contexto de saúde e direitos sexuais e reprodutivos e temáticas vinculadas ao HIV, atenção especial deve ser dada a pessoas vivendo com HIV, profissionais do sexo, pessoas trans, homens que fazem sexo com homens, pessoas que usam drogas e pessoas em prisões e ambientes fechados, com atenção adicional para adolescentes e jovens populações-chave. No entanto, na realidade brasileira essas são as pessoas com maior dificuldade de acesso aos serviços de saúde.

Em um material recente, a OMS ${ }^{(16)}$ recomenda que esferas nacionais trabalhem com o sistema de justiça criminal e parceiros da sociedade civil para emendar as leis e políticas nacionais que comprovadamente impedem as pessoas de acessar os serviços que precisam; reforçando que ações conjuntas e sinérgicas são necessárias para alcançar mudanças.

A maioria dos países da Região Europeia desenvolveu e começou a implementação de estratégias abrangentes de saúde sexual e reprodutiva. Foram introduzidas desde 1994, seguindo as recomendações e o Programa de Ação da Conferência Internacional para População e Desenvolvimento, organizada pelo UNFPA no Cairo, Egito. Geralmente incluem ações intersetoriais, especialmente com respeito a intervenções no setor educacional e juvenil, incluindo a prevenção da violência sexual. ${ }^{(16,17)}$

Um dos temas recorrentes das entrevistas foi a falta de automação do processo de acesso a PEP, ainda burocrático e analógico. Ao buscar por estratégias de eHealth ou mHealth sobre o tema, uma revisão(18) recente mostrou que existem muito poucas iniciativas dedicadas exclusivamente ao PEP, pois a maioria dos aplicativos aborda aspectos genéricos do HIV. As análises de objetivo e conteúdo mostram que esses aplicativos são muito semelhantes às estratégias tradicionais (livretos e sites) por usarem pouco ou nada da ampla gama de ferramentas que um smartphone pode oferecer. ${ }^{(19)}$

Em Singapura, ${ }^{(12)}$ autoridades governamentais fornecem informações diárias na grande mídia, usando grupos de Telegram e WhatsApp com médicos nos setores público e privado onde informações clínicas e logísticas mais detalhadas são compartilhadas e as autoridades usam sites para desmascarar a desinformação que circula.

A literatura sobre prevenção evidencia que a mudança de comportamentos individuais está articulada à mobilização comunitária e a transformações de contextos intersubjetivos. ${ }^{(20)} \mathrm{Na}$ utilização de quaisquer dos métodos preventivos, seria importante - no âmbito da política de prevenção - o desenvolvimento de ações voltadas à mobilização comunitária e à promoção do debate público acerca da prevenção, dimensões ainda pouco exploradas. 


\section{Conclusão}

O acesso à PEP é dificultado pelo desconhecimento sobre a profilaxia, o que impossibilita sua busca, a centralização dos serviços de saúde e estigmas que permeiam as estruturas dos serviços de saúde. Aspectos burocráticos, como a centralização da profilaxia em centros específicos, criam barreiras físicas que impedem que as pessoas possam iniciá-la em tempo, além de contribuir para barreiras intangíveis, como preconceitos difundidos entre profissionais e usuários do serviço e até mesmo políticas públicas. Esses achados apontam para problemas e, consequentemente, soluções que ultrapassam ações pontuais e individualistas. Ainda que sejam complementares e importantes, não abarcam os reais problemas. Alterar as estruturas dos serviços de HIV é necessário para combater o estigma que serviços carregam, agilizá-los e aproximá-los das comunidades.

\section{Agradecimentos}

Este estudo faz parte da tese de doutorado de Artur Acelino Francisco Luz Nunes Queiroz, que é financiada por meio de bolsa de pós-graduação do CNPq (Conselho Nacional de Desenvolvimento Científico e Tecnológico).

\section{Colaborações}

Queiroz AAFL, Mendes IAC e Dias S colaboraram com a concepção do projeto, análise e interpretação dos dados, redação do artigo, revisão crítica relevante do conteúdo intelectual e aprovação final da versão a ser publicada.

\section{Referências}


4.2. Objetivo 2: Identificar tecnologias eletrônicas móveis disponíveis para a identificação, triagem e encaminhamento de pessoas expostas sexualmente ao HIV para serviços de saúde.

Publicado no periódico: JMIR Mhealth Uhealth 


\title{
mHealth Strategies Related to HIV Postexposure Prophylaxis Knowledge and Access: Systematic Literature Review, Technology Prospecting of Patent Databases, and Systematic Search on App Stores
}

Artur Acelino Francisco Luz Nunes Queiroz ${ }^{1,2^{*}}, \mathrm{BA}, \mathrm{MSc}$; Isabel Amélia Costa Mendes ${ }^{1 *}$, PhD; Simone de Godoy ${ }^{1^{*}}$, $\mathrm{PhD}$; Luís Velez Lapão ${ }^{3 *}, \mathrm{PhD}$; Sónia Dias ${ }^{2^{*}}, \mathrm{PhD}$

\footnotetext{
${ }_{1}^{1}$ Department of General and Specialized Nursing, Escola de Enfermagem de Ribeirão Preto, Universidade de São Paulo, Ribeirão Preto, Brazil

${ }^{2}$ Escola Nacional de Saúde Pública, Universidade Nova de Lisboa, Lisboa, Portugal

${ }^{3}$ Global Health and Tropical Medicine, Instituto de Higiene e Medicina Tropical, Universidade Nova de Lisboa, Lisboa, Portugal

*all authors contributed equally
}

\section{Corresponding Author:}

Artur Acelino Francisco Luz Nunes Queiroz, BA, MSc

Department of General and Specialized Nursing, Escola de Enfermagem de Ribeirão Preto

Universidade de São Paulo

R Prof Hélio Lourenço, 3900 - Vila Monte Alegre

Ribeirão Preto, 14040-902

Brazil

Phone: 551633154321

Email: arturqueiroz@usp.br

\begin{abstract}
Background: Globally, the number of HIV cases continue to increase, despite the development of multiple prevention strategies. New cases of HIV have been reported disproportionately more in men who have sex with men and other vulnerable populations. Issues such as internalized and structural homophobia prevent these men from accessing prevention strategies such as postexposure prophylaxis (PEP). Mobile health (mHealth) interventions are known to be one of the newest and preferred options to enhance PEP knowledge and access.
\end{abstract}

Objective: The aim of this study was to identify and analyze the mobile apps addressing PEP for HIV infections.

Methods: We conducted a descriptive exploratory study in 3 sequential phases: systematic literature review, patent analysis, and systematic search of app stores. For the systematic review, we followed the Preferred Reporting Items for Systematic Reviews and Meta-Analyses guidelines adapted for an integrative review in the databases of PubMed, Web of Knowledge, Scopus, Cochrane, Embase, Science Direct, Eric, Treasure, and CINAHL. The patent analysis was performed by exploring the databases of the Brazilian National Institute of Industrial Property, the United States Patent and Trademark Office, and the European Patent Office. For the systematic search, we analyzed mHealth apps related to HIV in 2 major app libraries, that is, Google Play Store and App Store. The apps were evaluated by name, characteristics, functions, and availability in iPhone operating system/Android phones.

Results: We analyzed 22 studies, of which 2 were selected for the final stage. Both studies present the use of apps as mHealth strategies aimed at improving the sexual health of men who have sex with men, and they were classified as decision support systems. The search in the patent databases showed only 1 result, which was not related to the topic since it was a drug intervention. In the app libraries, 25 apps were found and analyzed, with $15(60 \%)$ apps available for Android systems but only 3 (12\%) addressing PEP. In general, the apps inform about HIV and HIV prevention and treatment, with the focus users being health care providers, people with HIV, or the general population, but they have only limited features available, that is, mainly text, images, and videos. The 3 apps exclusively focusing on PEP were created by researchers from Brazilian universities.

Conclusions: Our review found no connection between the scientific studies, registered patents, and the available apps related to PEP; this finding indicates that these available apps do not have a theoretical or a methodological background in their creation. Thus, since the scientific knowledge on HIV is not translated into technological products, preventing the emergence of new 
infections, especially in the more vulnerable groups, is difficult. In the future, researchers and the community must work in synergy to create more mHealth tools aimed at PEP.

(JMIR Mhealth Uhealth 2021;9(2):e23912) doi: 10.2196/23912

\section{KEYWORDS}

HIV; eHealth; mHealth; postexposure prophylaxis; PEP; prevention; mobile phone

\section{Introduction}

The efforts to globally fight HIV/AIDS have been increasing in the past 30 years since the first HIV global epidemic. There has been a steady global progress in the reduction of AIDS-related deaths over the last decade but a slower progress in the reduction of new HIV infections. However, epidemiological trends have remained consistent over the years, with men who have sex with men being disproportionately more affected by HIV than other populations [1].

In 2014, the UNAIDS (Joint United Nations Program on HIV/AIDS) launched a 90-90-90 target to combat AIDS as a public health threat by 2030, and the joint action of country-led and region-led efforts was required to establish this target for HIV treatment scale-up. The goal was that, by $2020,90 \%$ of all people with HIV will know their HIV-positive status, $90 \%$ of all people diagnosed with HIV will have access to antiretroviral treatment, and $90 \%$ of all people under treatment will have an undetectable viral load [2]. According to the most recent UNAIDS data, 1.7 million new HIV infections were reported in 2019-more than 3 times the 2020 target. This incidence increased by 690,000 in 2020, indicating that we are very far from ending the HIV global epidemic [1]. A series of new tools complementary to the use of condoms and treatment as a form of prevention has been introduced to achieve the 90-90-90 goals, with emphasis on postexposure prophylaxis (PEP) and pre-exposure prophylaxis (PrEP).

PrEP is the daily use of a combination of antiretrovirals (tenofovir plus emtricitabine) to prevent the acquisition of HIV infection. The World Health Organization recommends that people at substantial risk of HIV infection should be offered PrEP as an additional prevention choice as part of comprehensive prevention [1]. PEP is short-term antiretroviral treatment that is one of the key prevention strategies in reducing the likelihood of HIV infection after potential (possible) exposure to the virus, either occupationally or through sexual intercourse, and the success rate of this strategy has been reported to be $89 \%$ [3].

PEP is of crucial importance in preventing HIV infections since it can be used even in high-risk situations, for example, during condom tear in sexual intercourse, contact with partners with a high viral or unknown viral load, and even in cases of sexual violence. The main challenge for the consolidation of PEP as one of the main preventive measures against HIV infections is the need for a specific initiation period-2 hours being considered as optimal and up to 72 hours as acceptable. Therefore, this situation is considered as an emergency [3].

The literature points out that, although crucial, data on the use of PEP are still incipient, as they are collected retrospectively instead of systematically [3,4]. Vulnerable populations for infection control are the main potential users of this strategy. However, for this purpose, they need to be properly welcomed into the health care service. There is evidence that serodiscordant couples undergoing treatment are unaware of the option of adhering to PEP for HIV prevention [4] and men who have sex with men do not identify risk situations for exposure to HIV [5].

Mobile health (mHealth) interventions have emerged as a promising tool to support disease self-management among people living with HIV, especially by promoting drug adherence and information sources. mHealth technologies have shown potential in improving patients' communication with their health care providers by offering education and supporting the management of various chronic conditions, including diabetes, cardiovascular disease, and HIV infections. However, for mHealth interventions to be effective, they need to be developed and optimized with the needs of people in mind [6]. Despite this potential, little is known about the usage of this tool to work toward the UNAIDS goals of preventing new infections or improving PEP usage.

In light of the current COVID-19 pandemic, the prevention of HIV infections is facing unprecedented barriers such as shortage of health care professionals and resources and physical distancing from health care services. To overcome this challenge, health care systems and health care professionals are seeking new strategies, particularly eHealth and mHealth strategies, for the prevention of HIV spread [7]. Thus, in this study, we aimed to identify and analyze mobile apps that address PEP.

\section{Methods}

\section{Study Design}

We conducted a descriptive exploratory study [8] in 3 sequential phases: systematic literature review, patent analysis, and systematic search on app stores. An integrative review is an important resource for evidence-based practices and provides systematic techniques to summarize the literature on a given subject, thereby providing a unique view from different perspectives [9]. As a complement, studies [10] on technology prospecting refer to activities of technology determination focused on technological changes in functional capacity or on when the technologies were created and their innovativeness. This type of study aims at incorporating information into the technology management process, thereby predicting the possible future states of the technology or conditions that affect its contribution to established goals. Therefore, prospecting studies are used to determine the current state of a certain technological area and to generate information about its trajectory, future, and 
market trends, as well as to perceive weaknesses in certain areas [11]. In other words, these studies portray what is being recently done and can be used to point out the gaps that still need to be addressed. Thus, these studies constitute fundamental components to enhance the capacity to guide and subsidize the organization of innovation systems, transcending the business scope toward the academic environment.

\section{Phase 1: Literature Review}

To conduct a comprehensive review, we followed the Preferred Reporting Items for Systematic Reviews and Meta-Analyses guidelines adapted for an integrative review owing to the nature of our objective and the studies related to it. We followed the following steps: (1) identifying the research question, (2) surveying relevant studies, (3) selecting the studies, (4) organizing the data, and (5) collecting, summarizing, and reporting the results [9]. Thus, we defined the mobile apps that were developed to assist in the usage of PEP as the research subject. We then used medical subject heading descriptors to search the PubMed databases through the PubMed portal of the National Library of Medicine, Web of Knowledge, Scopus, Cochrane, Embase, Science Direct, Eric, Treasure, and CINAHL by using a combination of descriptors and keywords. The defined inclusion criteria were primary studies with full text available published until July 2020, in any language. The exclusion criteria were book chapters, doctoral dissertations, master's thesis, and technical reports in the initial search [8]. This research was conducted from June 1, 2020 to June 30, 2020 by a researcher with expertise in HIV prevention and systematic reviews. We used the following descriptors: HIV, Post-Exposure Prophylaxis, and Mobile Phone applications. Boolean operators were used to separate the keywords and descriptors (Table 1).

Table 1. Search strategy in each database and the selected studies. ${ }^{\mathrm{a}}$

\begin{tabular}{|c|c|c|}
\hline Database & Search strategy & Retrieved studies $(\mathrm{N}=22), \mathrm{n}$ \\
\hline PubMed & $\begin{array}{l}\text { (“post-exposure prophylaxis”[MeSH Terms] OR ("post-exposure”[All Fields] AND } \\
\text { "prophylaxis”[All Fields]) OR “post-exposure prophylaxis”[All Fields] OR ("post”[All } \\
\text { Fields] AND “exposure”[All Fields] AND “prophylaxis”[All Fields]) OR “post exposure } \\
\text { prophylaxis”[All Fields]) AND (“mobile applications”[MeSH Terms] OR ("mobile”[All } \\
\text { Fields] AND "applications"[All Fields]) OR “mobile applications"[All Fields]) }\end{array}$ & 5 \\
\hline Scopus & (post-exposure AND prophylaxis AND HIV AND mobile AND applications) & 3 \\
\hline Web of Science & 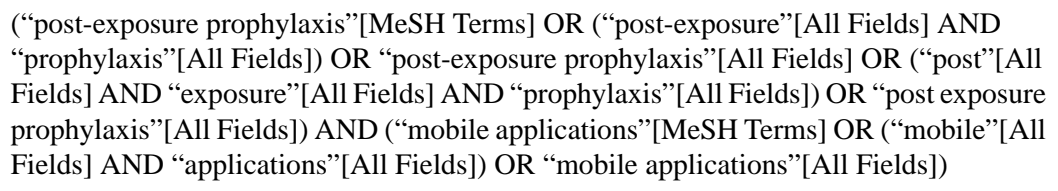 & 1 \\
\hline CINAHL & $\begin{array}{l}\text { Post-exposure prophylaxis or PEP or non-occupational post-exposure prophylaxis (nPEP) } \\
\text { AND mobile applications }\end{array}$ & 7 \\
\hline Cochrane & Post-exposure prophylaxis AND mobile applications & 2 \\
\hline Embase & Post-exposure prophylaxis AND mobile applications & 3 \\
\hline Science Direct & $\begin{array}{l}\text { (“post-exposure prophylaxis”[MeSH Terms] OR ("post-exposure”[All Fields] AND } \\
\text { "prophylaxis”[All Fields]) OR “post-exposure prophylaxis”[All Fields] OR ("post”[All } \\
\text { Fields] AND “exposure”[All Fields] AND “prophylaxis”[All Fields]) OR “post exposure } \\
\text { prophylaxis”[All Fields]) AND (“mobile applications”[MeSH Terms] OR ("mobile”[All } \\
\text { Fields] AND "applications"[All Fields]) OR “mobile applications”[All Fields]) }\end{array}$ & 1 \\
\hline Eric & Post-exposure prophylaxis AND mobile applications & 0 \\
\hline Treasure & HIV AND post-exposure prophylaxis AND mobile applications & 0 \\
\hline
\end{tabular}

${ }^{\mathrm{a}}$ Source: Direct research.

Two investigators conducted the analyses of the papers and discussed their inclusion during web-based meetings to reach a consensus. The titles and abstracts were read, followed by the application of the inclusion and exclusion criteria. For papers with no abstracts or if the abstracts did not permit paper exclusion or inclusion, the papers were read. The studies were analyzed, evaluating their direct relationship with the research question, along with the method, type of investigation, outcomes, objectives, sample, results, and conclusions. Duplicate studies were excluded. In total, 2 papers were selected (Figure $1)$. 
Figure 1. Flow diagram for the selection process following the Preferred Reporting Items for Systematic Reviews and Meta-Analyses guideline.

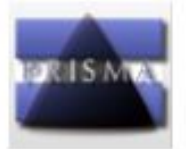

\section{PRISMA 2009 Flow Diagram}

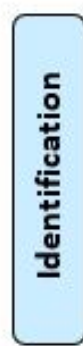

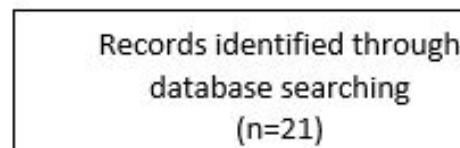

$(n=21)$

Records after duplicates removed

$(n=10)$
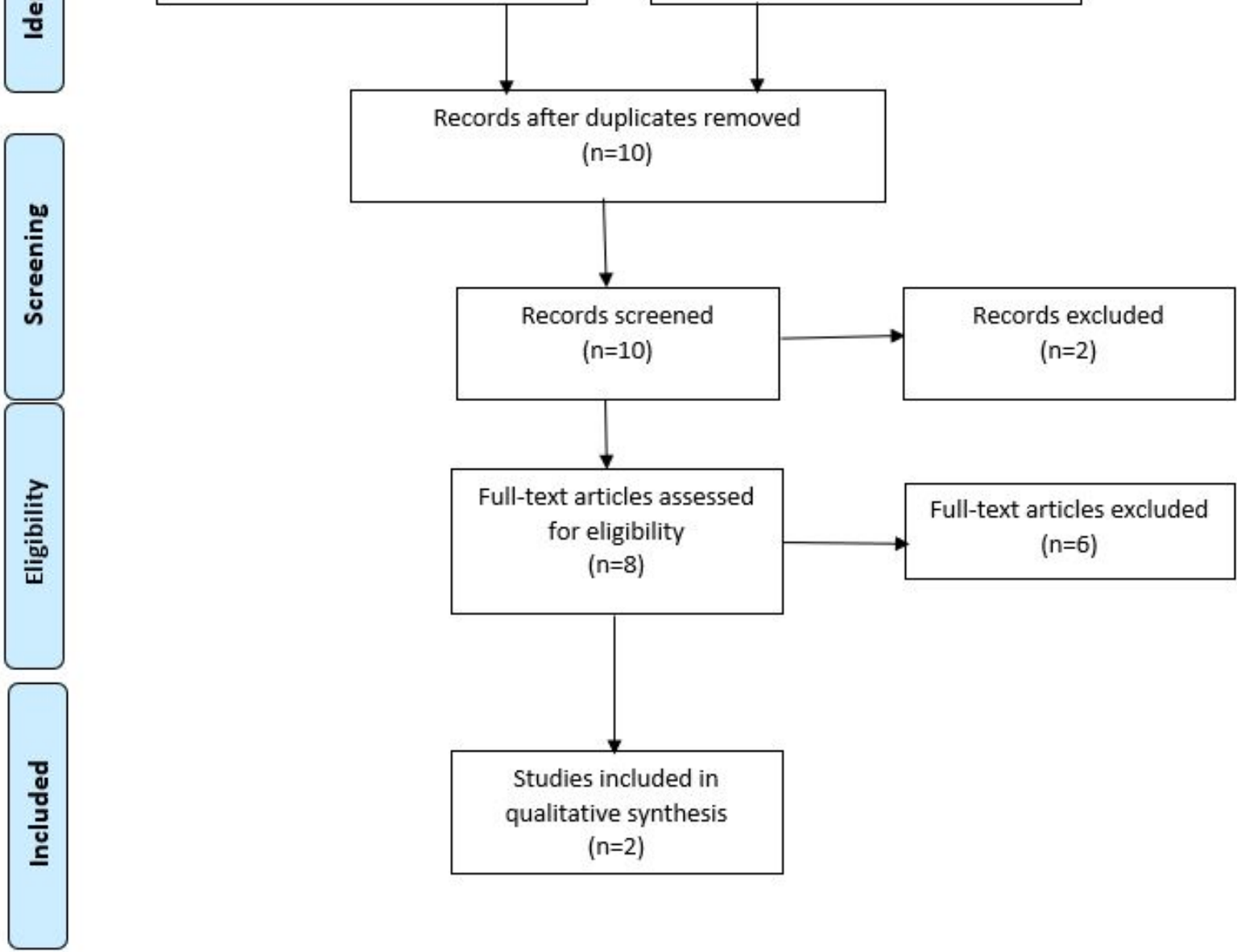

\section{Phase 2: Technology Prospecting of Patent Databases}

To execute this stage of the study, we focused on the countries that showed the highest production of mobile apps on PEP (based on the results of the integrative review) to define the patent databases that could be included. The patent databases that were selected were the National Institute of Industrial Property (INPI), which is the official government body responsible for the industrial property rights in Brazil, the United States Patent and Trademark Office (USPTO), which is the federal agency for granting US patents and registering trademarks, and Espacenet, which is the database of the European Patent Office, with documents from more than 90 countries. The duties of INPI include trademark registration, patent grants, technology transfer, and franchising contract registration. The search, retrieval, and export of patents on mobile apps related to PEP for HIV were carried out on July 4, 2020. In this stage, to search the INPI and Espacenet databases, structured search strategies were used with the Boolean operator "and" and the truncation to the right of type "*”". These operators were used in conjunction with the keywords to maximize the possibilities of finding the patent documents on the technology of interest. The keywords used in the searches are described below: "(HIV) AND Post-Exposure Prophylaxis AND Mobile Applications" in the "summary" field in the advanced search engine of the INPI patent database. In the Espacenet Advanced Search Builder, the keywords "HIV AND Post-Exposure Prophylaxis AND Mobile Applications" were used in the "keyword (s) in title or abstract" field. The same keywords but without the truncation features were entered in the USPTO search box. 


\section{Phase 3: App Search}

To complement the previous stage, we performed an analysis in 2 major app libraries on July 4, 2020: Google Play Store (for Android apps) and App Store (for Apple). This step enabled us to understand which apps exist, their objectives, functions, who produces them, whether these apps correspond to the published studies (phase 1), and the patents registered (phase 2). For this purpose, we used the following keywords: "HIV Post-Exposure Prophylaxis" in the Google Play Store and "HIV" and "Post-Exposure Prophylaxis" in the App Store. We found 35 apps for Android phones and 4 apps for Apple phones with these keywords. We categorized the selected apps according to the World Health Organization [12] classification for eHealth initiatives: call centers in medical care, free emergency telephone services, emergency apps for public health, mobile telemedicine services, phone reminders, community mobilization for health promotion, treatment compliance initiatives, patient records systems, systems of initiatives for information, apps for patient monitoring, mobile devices for health research, surveillance system, awareness systems, and decision support systems.

\section{Data Analysis}

The apps were evaluated by name, characteristics, functions, and availability for the main systems (iPhone operating system or Android) (Table 2). Patent registrations were analyzed descriptively according to the information retrieved from the patent databases, titles, descriptions, and applicants/inventors. This research exempted the evaluation by an ethics committee because it did not involve human beings, according to the determinations of the Brazilian decrees 466/12 and 510/16. 
Table 2. Distribution of the apps according to name, developer, main purpose, hosted platform, and classification. ${ }^{\text {a }}$

\begin{tabular}{|c|c|c|c|c|c|c|c|}
\hline App & App Developer & Aim of app & $\begin{array}{l}\text { Address postex- } \\
\text { posure } \\
\text { prophylaxis } \\
\text { (Yes/No) }\end{array}$ & $\begin{array}{l}\text { Target } \\
\text { population }\end{array}$ & Country & $\begin{array}{l}\text { Phone } \\
\text { operating } \\
\text { system }\end{array}$ & $\begin{array}{l}\text { World Health } \\
\text { Organization } \\
\text { classification }\end{array}$ \\
\hline PEPtec & EEUSP Saúde Coletiva & $\begin{array}{l}\text { This is an app that } \\
\text { assists in the care } \\
\text { of people who } \\
\text { have experienced } \\
\text { situations with a } \\
\text { potential risk of } \\
\text { HIV infection. }\end{array}$ & Yes & $\begin{array}{l}\text { General } \\
\text { population }\end{array}$ & Brazil & Android & $\begin{array}{l}\text { Mobile } \\
\text { telemedicine } \\
\text { services }\end{array}$ \\
\hline PEPusuário & EEUSP Saúde Coletiva & $\begin{array}{l}\text { Assist the patient } \\
\text { in using } \\
\text { postexposure pro- } \\
\text { phylaxis to com- } \\
\text { plete the 28-day } \\
\text { recommended } \\
\text { measurement. }\end{array}$ & Yes & $\begin{array}{l}\text { People using } \\
\text { postexposure } \\
\text { prophylaxis }\end{array}$ & Brazil & Android & $\begin{array}{l}\text { Treatment } \\
\text { compliance } \\
\text { initiatives }\end{array}$ \\
\hline $\begin{array}{l}\text { HIV Oral PrEP } \\
\text { Implementation } \\
\text { Tool }\end{array}$ & Jhpiego Organization & $\begin{array}{l}\text { To support the } \\
\text { implementation of } \\
\text { pre-exposure pro- } \\
\text { phylaxis among a } \\
\text { range of } \\
\text { populations in dif- } \\
\text { ferent settings. }\end{array}$ & No & Care providers & United States & Android & $\begin{array}{l}\text { Community } \\
\text { mobilization for } \\
\text { health } \\
\text { promotion }\end{array}$ \\
\hline $\begin{array}{l}\text { Florida HIV/AIDS } \\
\text { Hotline }\end{array}$ & Wellsky & $\begin{array}{l}\text { Provides } \\
\text { connection to al- } \\
\text { most } 400 \text { related } \\
\text { HIV care services } \\
\text { in Florida. }\end{array}$ & No & $\begin{array}{l}\text { People living } \\
\text { with HIV and } \\
\text { general } \\
\text { population }\end{array}$ & United States & Android & $\begin{array}{l}\text { Call centers in } \\
\text { medical care }\end{array}$ \\
\hline PreP4U & HealthHIV & $\begin{array}{l}\text { A resource for pre- } \\
\text { exposure prophy- } \\
\text { laxis to prevent } \\
\text { HIV information. }\end{array}$ & No & $\begin{array}{l}\text { General } \\
\text { population }\end{array}$ & United States & Android & $\begin{array}{l}\text { Systems of } \\
\text { initiatives for } \\
\text { information }\end{array}$ \\
\hline TánaMão & Metasix Tecnologia & $\begin{array}{l}\text { This app presents } \\
\text { an illustrative } \\
\text { questionnaire with } \\
\text { simple questions, } \\
\text { which can calcu- } \\
\text { late the risk rate of } \\
\text { HIV infection. }\end{array}$ & Yes & $\begin{array}{l}\text { General } \\
\text { population }\end{array}$ & Brazil & Android & $\begin{array}{l}\text { Awareness } \\
\text { systems }\end{array}$ \\
\hline EoHIV & $\begin{array}{l}\text { GN1 sistemas e publica- } \\
\text { coes }\end{array}$ & $\begin{array}{l}\text { Providing } \\
\text { information to } \\
\text { health workers can } \\
\text { enhance self-care } \\
\text { and improve adher- } \\
\text { ence to postexpo- } \\
\text { sure prophylaxis } \\
\text { due to biological } \\
\text { exposure. }\end{array}$ & Yes & Care providers & Brazil & Android & $\begin{array}{l}\text { Systems of } \\
\text { initiatives for } \\
\text { information }\end{array}$ \\
\hline $\begin{array}{l}\text { AIDSinfo Drug } \\
\text { Database }\end{array}$ & $\begin{array}{l}\text { National Library of } \\
\text { Medicine at National In- } \\
\text { stitutes of Health }\end{array}$ & $\begin{array}{l}\text { Provides } \\
\text { information about } \\
\text { antiretroviral drugs }\end{array}$ & No & $\begin{array}{l}\text { Care providers } \\
\text { and people } \\
\text { living with } \\
\text { HIV }\end{array}$ & United States & Android & $\begin{array}{l}\text { Systems of } \\
\text { initiatives for } \\
\text { information }\end{array}$ \\
\hline HIV Dating & MyDatingDirectory & $\begin{array}{l}\text { Dating app for } \\
\text { people living with } \\
\text { HIV }\end{array}$ & No & $\begin{array}{l}\text { People living } \\
\text { with HIV }\end{array}$ & Switzerland & Android & $\mathrm{N} / \mathrm{A}^{\mathrm{b}}$ \\
\hline
\end{tabular}




\begin{tabular}{|c|c|c|c|c|c|c|c|}
\hline App & App Developer & Aim of app & $\begin{array}{l}\text { Address postex- } \\
\text { posure } \\
\text { prophylaxis } \\
\text { (Yes/No) }\end{array}$ & $\begin{array}{l}\text { Target } \\
\text { population }\end{array}$ & Country & $\begin{array}{l}\text { Phone } \\
\text { operating } \\
\text { system }\end{array}$ & $\begin{array}{l}\text { World Health } \\
\text { Organization } \\
\text { classification }\end{array}$ \\
\hline $\begin{array}{l}\text { Nigeria HIV } \\
\text { Guideline }\end{array}$ & $\begin{array}{l}\text { Powered by Management } \\
\text { Sciences for Health }\end{array}$ & $\begin{array}{l}\text { Provides general } \\
\text { and specific } \\
\text { guidance for HIV } \\
\text { prevention and } \\
\text { treatment. }\end{array}$ & No & Care providers & Nigeria & Android & $\begin{array}{l}\text { Systems of } \\
\text { initiatives for } \\
\text { information }\end{array}$ \\
\hline PreParaDXS & $\begin{array}{l}\text { Sociedad Española de } \\
\text { Farmacia Hospitalaria }\end{array}$ & $\begin{array}{l}\text { Information about } \\
\text { HIV and other } \\
\text { sexually transmit- } \\
\text { ted infections, HIV } \\
\text { testing, pre-expo- } \\
\text { sure prophylaxis, } \\
\text { and other preven- } \\
\text { tion methods. }\end{array}$ & Yes & $\begin{array}{l}\text { General } \\
\text { population }\end{array}$ & Spain & Android & $\begin{array}{l}\text { Systems of } \\
\text { initiatives for } \\
\text { information }\end{array}$ \\
\hline $\begin{array}{l}\text { Beat AIDS - 50+ } \\
\text { Tips for HIV pre- } \\
\text { vention }\end{array}$ & Tipsbook & $\begin{array}{l}\text { Provides informa- } \\
\text { tion about HIV } \\
\text { prevention }\end{array}$ & Yes & $\begin{array}{l}\text { General } \\
\text { population } \\
\text { and people } \\
\text { living with } \\
\text { HIV }\end{array}$ & India & Android & $\begin{array}{l}\text { Systems of } \\
\text { initiatives for } \\
\text { information }\end{array}$ \\
\hline $\begin{array}{l}\text { HIV Instant Test } \\
\text { and Guide (2019) }\end{array}$ & JOE Technologies & Information app & No & $\begin{array}{l}\text { General } \\
\text { population }\end{array}$ & United States & Android & $\begin{array}{l}\text { Systems of } \\
\text { initiatives for } \\
\text { information }\end{array}$ \\
\hline Life4me+ & $\begin{array}{l}\text { Life4me.plus fight to } \\
\text { AIDS, Hepatitis C, and } \\
\text { Tuberculosis }\end{array}$ & $\begin{array}{l}\text { The app } \\
\text { automatically re- } \\
\text { members testing } \\
\text { for sexually trans- } \\
\text { mitted } \\
\text { infections, taking } \\
\text { pre-exposure HIV } \\
\text { prevention medica- } \\
\text { tions, and taking } \\
\text { antiretroviral drugs } \\
\text { for HIV or hepati- } \\
\text { tis C. }\end{array}$ & No & $\begin{array}{l}\text { General } \\
\text { population }\end{array}$ & Switzerland & Android & $\begin{array}{l}\text { Phone } \\
\text { reminders }\end{array}$ \\
\hline Jilinde & Ubunifu Ltd & $\begin{array}{l}\text { To promote oral } \\
\text { pre-exposure pro- } \\
\text { phylaxis in Kenya }\end{array}$ & No & $\begin{array}{l}\text { General } \\
\text { population }\end{array}$ & Kenya & Android & $\begin{array}{l}\text { Awareness } \\
\text { systems }\end{array}$ \\
\hline Sintomas do HIV & Dev Galaxy Store & $\begin{array}{l}\text { Provides access to } \\
\text { the federal govern- } \\
\text { ment's guidelines } \\
\text { for medical prac- } \\
\text { tice on HIV/AIDS. }\end{array}$ & Yes & $\begin{array}{l}\text { General } \\
\text { population }\end{array}$ & Brazil & Android & $\begin{array}{l}\text { Systems of } \\
\text { initiatives for } \\
\text { information }\end{array}$ \\
\hline 2018 BHPS & $\begin{array}{l}\text { National Minority AIDS } \\
\text { Council, Inc }\end{array}$ & $\begin{array}{l}\text { To inform about } \\
\text { the third annual } \\
\text { Biomedical HIV } \\
\text { Prevention Sum- } \\
\text { mit. }\end{array}$ & No & $\begin{array}{l}\text { General } \\
\text { population }\end{array}$ & United States & Android & $\begin{array}{l}\text { Systems of } \\
\text { initiatives for } \\
\text { information }\end{array}$ \\
\hline Be-PrEP-ared & Frederik Matthesstraat & $\begin{array}{l}\text { To support pre-ex- } \\
\text { posure prophylaxis } \\
\text { users in correct us- } \\
\text { age }\end{array}$ & No & $\begin{array}{l}\text { General } \\
\text { population } \\
\text { and pre-expo- } \\
\text { sure } \\
\text { prophylaxis } \\
\text { users }\end{array}$ & Netherlands & Android & $\begin{array}{l}\text { Apps for patient } \\
\text { monitoring }\end{array}$ \\
\hline HIV and Aids & $\begin{array}{l}\text { Focus Medica India Pvt. } \\
\text { Ltd }\end{array}$ & $\begin{array}{l}\text { Animated videos } \\
\text { about HIV and } \\
\text { AIDS }\end{array}$ & No & $\begin{array}{l}\text { General } \\
\text { population }\end{array}$ & India & Android & $\begin{array}{l}\text { Systems of } \\
\text { initiatives for } \\
\text { information }\end{array}$ \\
\hline
\end{tabular}




\begin{tabular}{|c|c|c|c|c|c|c|c|}
\hline App & App Developer & Aim of app & $\begin{array}{l}\text { Address postex- } \\
\text { posure } \\
\text { prophylaxis } \\
\text { (Yes/No) }\end{array}$ & $\begin{array}{l}\text { Target } \\
\text { population }\end{array}$ & Country & $\begin{array}{l}\text { Phone } \\
\text { operating } \\
\text { system }\end{array}$ & $\begin{array}{l}\text { World Health } \\
\text { Organization } \\
\text { classification }\end{array}$ \\
\hline $\begin{array}{l}\text { HIV-Rx DDI } \\
\text { Check }\end{array}$ & John Faragon & $\begin{array}{l}\text { This app provides } \\
\text { an easy-to-use } \\
\text { Drug Interaction } \\
\text { mobile reference } \\
\text { based on the De- } \\
\text { partment of Health } \\
\text { and Human Ser- } \\
\text { vices Guidelines } \\
\text { for the Use of An- } \\
\text { tiretroviral drugs. }\end{array}$ & No & Care providers & United States & Android & $\begin{array}{l}\text { Decision } \\
\text { support } \\
\text { systems }\end{array}$ \\
\hline $\begin{array}{l}\text { Guia de teste do } \\
\text { HIV }\end{array}$ & Anadoluapps & $\begin{array}{l}\text { Information about } \\
\text { HIV }\end{array}$ & No & $\begin{array}{l}\text { General } \\
\text { population }\end{array}$ & Brazil & Android & $\begin{array}{l}\text { Systems of } \\
\text { initiatives for } \\
\text { information }\end{array}$ \\
\hline Połączenia & Program Stacja & $\begin{array}{l}\text { Information about } \\
\text { HIV }\end{array}$ & No & $\begin{array}{l}\text { General } \\
\text { population }\end{array}$ & Poland & Android & $\begin{array}{l}\text { Systems of } \\
\text { initiatives for } \\
\text { information }\end{array}$ \\
\hline $\begin{array}{l}\text { RIghtTime: RI's } \\
\text { Sexual Health app }\end{array}$ & $\begin{array}{l}\text { Rhode Island Department } \\
\text { of Health }\end{array}$ & $\begin{array}{l}\text { Offers information, } \\
\text { resources, and } \\
\text { videos on sexual } \\
\text { health topics in the } \\
\text { Rhode Island } \\
\text { region. }\end{array}$ & No & $\begin{array}{l}\text { General } \\
\text { population }\end{array}$ & United States & Android & $\begin{array}{l}\text { Systems of } \\
\text { initiatives for } \\
\text { information }\end{array}$ \\
\hline $\begin{array}{l}\text { How to Prevent } \\
\text { HIV Infection }\end{array}$ & NonitaDev & HIV information & No & $\begin{array}{l}\text { General } \\
\text { population }\end{array}$ & United States & Android & $\begin{array}{l}\text { Systems of } \\
\text { initiatives for } \\
\text { information }\end{array}$ \\
\hline $\begin{array}{l}\text { Long Exposure } \\
\text { Camera } 2\end{array}$ & $-^{\mathrm{c}}$ & $\begin{array}{l}\text { Long-exposure } \\
\text { photography }\end{array}$ & No & $\begin{array}{l}\text { Not related to } \\
\text { HIV content }\end{array}$ & - & Android & N/A \\
\hline MSACS & IT Hubtech Solutions & $\begin{array}{l}\text { To inform about } \\
\text { Maharashtra State } \\
\text { AIDS Control } \\
\text { Society in India }\end{array}$ & No & $\begin{array}{l}\text { General } \\
\text { population }\end{array}$ & India & Android & $\begin{array}{l}\text { Systems of } \\
\text { initiatives for } \\
\text { information }\end{array}$ \\
\hline $\begin{array}{l}\text { Pre-exposure pro- } \\
\text { phylaxis }\end{array}$ & $\begin{array}{l}\text { Pomorski Uniwersytet } \\
\text { Medyczny w Szczecinie }\end{array}$ & $\begin{array}{l}\text { To inform about } \\
\text { HIV, mainly pre- } \\
\text { exposure prophy- } \\
\text { laxis }\end{array}$ & No & $\begin{array}{l}\text { General } \\
\text { population } \\
\text { and } \\
\text { pre-exposure } \\
\text { prophylaxis } \\
\text { users }\end{array}$ & Poland & Android & $\begin{array}{l}\text { Systems of } \\
\text { initiatives for } \\
\text { information }\end{array}$ \\
\hline Yazi & Oluwatoni Fuwape & $\begin{array}{l}\text { To design } \\
\text { customized con- } \\
\text { doms }\end{array}$ & No & $\begin{array}{l}\text { General } \\
\text { population }\end{array}$ & United States & Android & N/A \\
\hline EDUC@AIDS & $\begin{array}{l}\text { Rvs Comunicação e Tec- } \\
\text { nologia }\end{array}$ & $\begin{array}{l}\text { To inform about } \\
\text { HIV }\end{array}$ & Yes & $\begin{array}{l}\text { General } \\
\text { population }\end{array}$ & Brazil & Android & $\begin{array}{l}\text { Systems of } \\
\text { initiatives for } \\
\text { information }\end{array}$ \\
\hline $\begin{array}{l}\text { Avoid HIV and } \\
\text { AIDS }\end{array}$ & Oualidosdev & $\begin{array}{l}\text { To inform about } \\
\text { HIV }\end{array}$ & No & $\begin{array}{l}\text { General } \\
\text { population }\end{array}$ & - & Android & $\begin{array}{l}\text { Systems of } \\
\text { initiatives for } \\
\text { information }\end{array}$ \\
\hline DIKA & DIKA & $\begin{array}{l}\text { To inform about } \\
\text { HIV }\end{array}$ & No & $\begin{array}{l}\text { General } \\
\text { population }\end{array}$ & Mozambique & Android & $\begin{array}{l}\text { Systems of } \\
\text { initiatives for } \\
\text { information }\end{array}$ \\
\hline
\end{tabular}




\begin{tabular}{|c|c|c|c|c|c|c|c|}
\hline App & App Developer & Aim of app & $\begin{array}{l}\text { Address postex- } \\
\text { posure } \\
\text { prophylaxis } \\
\text { (Yes/No) }\end{array}$ & $\begin{array}{l}\text { Target } \\
\text { population }\end{array}$ & Country & $\begin{array}{l}\text { Phone } \\
\text { operating } \\
\text { system }\end{array}$ & $\begin{array}{l}\text { World Health } \\
\text { Organization } \\
\text { classification }\end{array}$ \\
\hline$O C T P \circ B$ & Prometheus Studio & $\begin{array}{l}\text { To create a service } \\
\text { to increase the } \\
\text { availability of peer } \\
\text { counselors and } \\
\text { support groups for } \\
\text { people living with } \\
\text { HIV }\end{array}$ & No & $\begin{array}{l}\text { People living } \\
\text { with HIV }\end{array}$ & - & Android & $\begin{array}{l}\text { Community } \\
\text { mobilization for } \\
\text { health } \\
\text { promotion }\end{array}$ \\
\hline Candowell & Candowell & $\begin{array}{l}\text { A social network } \\
\text { that connects peo- } \\
\text { ple, content, and } \\
\text { purpose. }\end{array}$ & No & $\begin{array}{l}\text { Not related to } \\
\text { HIV }\end{array}$ & - & Android & N/A \\
\hline $\begin{array}{l}\text { Exposure Calcula- } \\
\text { tor }\end{array}$ & Evan Shortiss & $\begin{array}{l}\text { Light exposure cal- } \\
\text { culator }\end{array}$ & No & $\begin{array}{l}\text { Not related to } \\
\text { HIV }\end{array}$ & Spain & Android & N/A \\
\hline $\begin{array}{l}\text { Tratamentos e } \\
\text { Doenças }\end{array}$ & goGOODapp & $\begin{array}{l}\text { Inform about gener- } \\
\text { al infections }\end{array}$ & No & $\begin{array}{l}\text { General } \\
\text { population }\end{array}$ & - & Android & $\begin{array}{l}\text { Systems of } \\
\text { initiatives for } \\
\text { information }\end{array}$ \\
\hline $\begin{array}{l}\text { Monthly Prescrib- } \\
\text { ing Reference }\end{array}$ & Haymarket Media & $\begin{array}{l}\text { Inform about } \\
\text { general drugs, in- } \\
\text { cluding antiretrovi- } \\
\text { ral agents }\end{array}$ & Not & Care providers & United States & $\begin{array}{l}\text { iPhone } \\
\text { operating } \\
\text { system }\end{array}$ & $\begin{array}{l}\text { Systems of } \\
\text { initiatives for } \\
\text { information }\end{array}$ \\
\hline $\begin{array}{l}\text { ABC Medical } \\
\text { Notes Pro for Ex- } \\
\text { am }\end{array}$ & Pocketmednotes.com & $\begin{array}{l}\text { Medical guide for } \\
\text { medical students }\end{array}$ & No & $\begin{array}{l}\text { Medical } \\
\text { students }\end{array}$ & England & $\begin{array}{l}\text { iPhone } \\
\text { operating } \\
\text { system }\end{array}$ & $\begin{array}{l}\text { Mobile } \\
\text { telemedicine } \\
\text { services }\end{array}$ \\
\hline HIV 3D study & USaMau03 & $\begin{array}{l}\text { Shows the HIV } \\
\text { reference study and } \\
\text { 3D digital cell with } \\
\text { pins to show parts } \\
\text { of the HIV cell } \\
\text { structure. }\end{array}$ & No & Care providers & United States & $\begin{array}{l}\text { iPhone } \\
\text { operating } \\
\text { system }\end{array}$ & $\begin{array}{l}\text { Mobile } \\
\text { telemedicine } \\
\text { services }\end{array}$ \\
\hline $\begin{array}{l}\text { HIV Antibody } \\
\text { Database }\end{array}$ & Zentropy Software & $\begin{array}{l}\text { Display the se- } \\
\text { quence, structure, } \\
\text { and } \\
\text { neutralization data } \\
\text { for neutralizing an- } \\
\text { ti-HIV antibodies } \\
\text { and some HIV-1 } \\
\text { strains. It is meant } \\
\text { to be a tool for sci- } \\
\text { entists involved in } \\
\text { HIV } \\
\text { vaccine research. }\end{array}$ & No & $\begin{array}{l}\text { HIV } \\
\text { researchers }\end{array}$ & United States & $\begin{array}{l}\text { iPhone } \\
\text { operating } \\
\text { system }\end{array}$ & $\begin{array}{l}\text { Decision } \\
\text { support systems }\end{array}$ \\
\hline
\end{tabular}

${ }^{\mathrm{a} S}$ Source: Google Play Store (2019) and App Store (2019).

${ }^{\mathrm{b}} \mathrm{N} / \mathrm{A}$ : not applicable.

${ }^{\mathrm{c}}$ Not available.

\section{Results}

\section{Literature Review}

The exhaustive literature review resulted in only 2 studies that guided phases 2 and 3 of our study (Figure 1), and both originated in the United States. We focused on databases used in the United States even for phases 2 and 3 of this study. The 2 studies in the literature review report intervention measures - one being a pilot study for a randomized controlled trial and the second, a full randomized controlled trial. Both studies present the use of apps as mHealth strategies aimed at improving the sexual health of men who have sex with men and can be classified as "decision support systems" by the World Health Organization standards. Still, none of the studies were related to the apps found on Google Play Store and App Store.

Our first finding in the literature review was the system created by Sullivan et al [13], the HealthMindr, which included tools that help in self-assessment, recommend prevention strategies, help in finding and ordering condoms or HIV self-tests, and send reminders for prevention services, condom use, HIV 
testing, and screening for PrEP and PEP. All these features were provided with information that allowed users to choose the best form of prevention that fit their lifestyles. The second finding was the "MyPEEPS" app, a peer-based system developed by Hidalgo et al and Kuhns et al $[14,15]$ that provides educational information about HIV and sexually transmitted infections among young men who have sex with men, and it focused on raising awareness about minority stress (eg, due to sexual identity) and capacity building for condom use, emotional regulation, and negotiating interpersonal and substance-related risk; these skills were delivered through gamifications, scenarios, and role plays through 21 different activities.

\section{Technology Prospecting of Patent Databases}

Based on the finding that most studies in the systematic review were developed in the United States of America, a systematized search was executed in the chosen patent bases as described. Only 1 patent was found in the INPI database, but it was unrelated to the subject; it described the patent for an antiviral drug, thereby suggesting the lack of technological innovation efforts in PEP.

\section{Systematic Search on App Stores}

In total, 25 apps were retrieved, which were mostly developed for Android systems $(21 / 25,84 \%)$ in the United States (12/25, $48 \%$ ) or Brazil $(7 / 25,28 \%)$. In general, of the 25 apps on HIV and HIV prevention and treatment, $8(32 \%)$ target health care providers, 7 (28\%) target people living with HIV, and $23(92 \%)$ target the general population. The apps mainly consist of text, images, and videos $(15 / 25,60 \%)$. As 11 of the $25(46 \%)$ apps were centered on information, they were classified as "Mobile telemedicine services" and "Systems of initiatives for information" [11]. Only 3 (12\%) of them specifically focused on PEP (EoHIV, PEPtec, and PEPusuário), and these 3 apps were created by researchers from Brazilian universities.

EoHIV provides information for health care workers to assist in their self-care and improve adherence to PEP in the face of exposure to biological materials. The main functions of EoHIV are information provision about exposure to HIV, PEP and its side effects, planning about treatment, and provision of a calendar that enables the scheduling of the daily intake of the medication.

The focus of PEPusuário is to improve PEP adherence, thereby assisting the user to complete the 28-day treatment. This app also allows one to document the treatment start time, type of health care professional, and location. Information about the medication, its indications, and the location to access the medication are also available.

PEPtec is an app that assists people who have gone through a potential risk of HIV infection. Its design allows it to be used as a decision-making tool for receiving PEP by health care professionals in different settings such as emergency room, specialty clinic, basic health units, and maternity hospitals.

\section{Discussion}

\section{Overview of the Findings}

Our study combines a literature review and technological (prospecting and mobile app search) strategies to identify mobile apps for PEP. This analysis of 3 different data sources makes this study innovative in that it seeks to trace a relationship between the creation of scientific knowledge (phase 1) and its translation into technological products (phase 2 and phase 3 ). The lack of correspondence between the results in the 3 phases shows a gap between the construction of knowledge and its practical application.

The mapping of the mobile apps focused on PEP showed that there are very few initiatives dedicated exclusively for PEP, as most of the apps address HIV infections, with PEP being part of this broader content. The objective and content analyses of this mapping show that these apps are very similar to traditional strategies (booklets and websites) by using little or none of the wide range of tools a smartphone can offer. mHealth information initiatives are defined as services that provide access to health science publications or databases at points of care by using mobile devices. While relatively new to limited-income countries, these mHealth services are established in industrialized countries, where medical professionals are often equipped with advanced mobile devices [12]. Despite this, our data show a new trend since the exclusive PEP apps available in libraries were created in Brazil, a limited-income country. The Unified Health System in Brazil is the largest public health care system in the world, currently providing treatment and care for 150 million people. This system was part of the main HIV care network in 2018, wherein around 580,000 people living with HIV/AIDS received their antiretroviral drugs free of charge [16]. Its integration also extends to the country's teaching and research institutions, which explains the pioneering spirit in the creation of technologies, as we have reported.

As our review shows, even though there are only few apps related to PEP, future efforts should be made not only to create mHealth services but also to ensure that these services are evidence-based and reliable. A recent survey by the World Health Organization found that only $12 \%$ of the member states reported evaluating mHealth services and little was known about how to effectively evaluate these services [12]. Mobile telemedicine initiatives include consultations between health care providers and transmission of a patient's health-related data by using mobile devices.

The lack of innovative resources in the apps found can be a limiting factor for their use since they do not consist of attractive and engaging tools. However, one must take into consideration that more advanced mobile telemedicine initiatives require a significantly established infrastructure, fast telecommunication networks (ie, general packet radio services, 3G, 4G), and advanced technology, thereby making it challenging for growth and adoption by low- and middle-income countries [12], which have higher rates of HIV infection [1].

Governments are expressing interest in mHealth as a complementary strategy for strengthening the health care 
systems and for achieving health-related millennium development goals in low- and middle-income countries. This interest has taken the form of a series of mHealth deployments worldwide, which are providing early evidence of the potential for mobile and wireless technologies. mHealth is being applied in maternal and child health and in programs to reduce the burden of diseases linked with poverty, including HIV/AIDS, malaria, and tuberculosis. mHealth apps are being tested in diverse scenarios such as in improving timely access to emergency and general health services and information, managing patient care, reducing drug shortages at health clinics, and in enhancing clinical diagnosis and treatment compliance [12]. Most people using PEP or reporting knowledge of this strategy have already used it or belong to the lesbian, gay, bisexual, and transgender community (which historically has a closer relationship with HIV and its prevention forms), thereby placing a large part of the population in a window of "missed opportunity"- people who may have been candidates for this mHealth strategy but, due to lack of knowledge, could not access the service, especially heterosexual women, who are rarely contemplated by government campaigns on this subject [17].

Minority communities (by gender, sexuality, or ethnicity) are underrepresented in advertising, government, and even peer-to-peer education campaigns [18]. Evidence from a systematic review shows how lesbian, gay, bisexual, transgender, and queer + youth showed good adherence to tools tailored specifically for them. Digital health interventions have the potential to improve health disparities in this population, which in turn, would impact HIV transmission and prevention [19]. mHealth services offered to the public can help reach a larger population. However, when the applicability of the mHealth services is restricted, it becomes less attractive to the user. All the apps found in the literature are aimed and designed for men who have sex with men-a vulnerable population that is dismissed for large public health care or governmental initiatives [20]. Specially, young men who have sex with men are more prone to use eHealth and mHealth tools as ways to manage their own health similar to how they use other apps to tackle daily life issues [21]. However, there is a shortage of apps designed for other populations such as young women or transgender individuals. Evidence has shown that young people from sexual minorities, especially men who have sex with men, who perceive themselves within patterns of risky behavior are more likely to use the internet, especially on their smartphones to seek information about sexual health [22]. The combination of practicality, speed, and privacy make this tool an ideal way to deliver interventions and information. The fact that these individuals are so young is crucial in the strategic thinking of stopping the emergence of new infections; therefore, proper development of several tools based on scientific principles is critical. Despite the widespread promotion of technology-based interventions, evidence supporting their effectiveness in addressing noncommunicable diseases has not reached a consensus yet. Evaluations of apps and web-based programs as ways to deliver health interventions have reported that these technologies are no more effective than paper-based approaches or offer no additional benefit as an adjunct intervention. Although recent systematic reviews of eHealth and mHealth interventions targeting health behaviors provide some evidence of the short-term benefits, the effects are modest and long-term efficacy is yet to be established [21].

One of our main findings is that there is no correspondence between the 3 data sources assessed (scientific databases, patent databases, and mobile app libraries), which indicates that the scientific knowledge discovered and validated does not have the corresponding technology for implementation and most technologies that are available are not supported with appropriate methodological rigor.

\section{Limitations}

Our study has the following limitations. First, even though we did a thorough search on the apps, these results did not include all the existing app libraries. However, our data are still relevant because they are obtained from App Store and Google Play Store, which are the 2 main app libraries. Second, it is possible that other apps that address this topic exist but they did not appear in our search because of the specific combination of words. We used the best possible combination to find as many apps as possible with a focus on PEP because of its specific characteristics and unique importance in HIV prevention.

\section{Conclusion}

Our study demonstrates the lack of mHealth interventions for PEP. The apps that do exist are still focused on delivering information about HIV, and no initiative has been taken to improve access to further HIV interventions. These apps are deeply focused on the traditional format of compiling and organizing HIV information, without providing support for action. Thus, there is no available approach to prevent the emergence of new infections, especially in the more vulnerable groups (such as young lesbian, gay, bisexual, transgender) that already have high adherence to eHealth and mHealth interventions. Our review found no connection between scientific studies, registered patents, and the available apps, thereby indicating that the available apps do not have a theoretical or a methodological background in their creation. The accuracy and quality of these apps should be explored in future studies. Researchers and the community must work in synergy to create more mHealth tools aimed at PEP.

\section{Acknowledgments}

This study is part of AQ's doctoral thesis, which is funded through the CNPq (National Council for Scientific and Technological Development) postgraduate scholarship. 


\section{Authors' Contributions}

AQ was responsible for the conception and design of the study, analysis and interpretation of data, and writing of the paper. IM and LL provided the theoretical and methodological background for the study. SD was responsible for ensuring the accuracy and integrity of all aspects of this study. All authors reviewed the final manuscript.

\section{Conflicts of Interest}

None declared.

\section{References}

1. UNAIDS data 2020. URL: https://www.unaids.org/sites/default/files/media asset/2020 aids-data-book en.pdf [accessed 2002-02-21]

2. Levi J, Raymond A, Pozniak A, Vernazza P, Kohler P, Hill A. Can the UNAIDS 90-90-90 target be achieved? A systematic analysis of national HIV treatment cascades. BMJ Glob Health 2016;1(2):e000010 [FREE Full text] [doi: 10.1136/bmjgh-2015-000010] [Medline: 28588933]

3. Irvine C, Egan KJ, Shubber Z, Van Rompay KKA, Beanland RL, Ford N. Efficacy of HIV Postexposure Prophylaxis: Systematic Review and Meta-analysis of Nonhuman Primate Studies. Clin Infect Dis 2015 Jun 01;60 Suppl 3:S165-S169. [doi: 10.1093/cid/civ069] [Medline: 25972498]

4. Koblin BA, Usher D, Nandi V, Tieu H, Bravo E, Lucy D, et al. Post-exposure Prophylaxis Awareness, Knowledge, Access and Use Among Three Populations in New York City, 2016-17. AIDS Behav 2018 Aug;22(8):2718-2732. [doi: 10.1007/s10461-018-2175-5] [Medline: 29858737]

5. Dolezal C, Frasca T, Giguere R, Ibitoye M, Cranston RD, Febo I, et al. Awareness of Post-Exposure Prophylaxis (PEP) and Pre-Exposure Prophylaxis (PrEP) Is Low but Interest Is High Among Men Engaging in Condomless Anal Sex With Men in Boston, Pittsburgh, and San Juan. AIDS Educ Prev 2015 Aug;27(4):289-297 [FREE Full text] [doi: 10.1521/aeap.2015.27.4.289] [Medline: 26241380]

6. Handel MJ. mHealth (mobile health)-using Apps for health and wellness. Explore (NY) 2011;7(4):256-261. [doi: 10.1016/j.explore.2011.04.011] [Medline: 21724160]

7. Lapão LV. The Nursing of the Future: combining Digital Health and the Leadership of Nurses. Rev Lat Am Enfermagem 2020 Jun 19;28:e3338 [FREE Full text] [doi: 10.1590/1518-8345.0000.3338] [Medline: 32578758]

8. Mesquita A, Zamarioli C, Carvalho E. The use of robots in nursing care practices: an exploratory-descriptive study. Online Braz J Nurs. 2016. URL: http://www.objnursing.uff.br/index.php/nursing/article/view/5395 [accessed 2020-02-21]

9. Mendes K, Silveira R, Galvão C. Revisão integrativa: método de pesquisa para a incorporação de evidências na saúde e na enfermagem. Texto contexto - enferm 2008 Dec;17(4):758-764 [FREE Full text] [doi: 10.1590/S0104-07072008000400018]

10. Santos MM, Coelho GM, Santos DM, Filho LF. Prospecção de tecnologias de futuro: métodos, técnicas e abordagens. Parcerias estratégicas. 2010. URL: http://seer.cgee.org.br/index.php/parcerias estrategicas/article/view/253 [accessed 2020-01-01]

11. Ceccim R, Kreutz J. Prospecção de modelos tecnoassistenciais na atenção básica: protocolo de pesquisa colaborativa multissituada na Educação em Saúde Coletiva. In-formes da atenção básica: aprendizados de intensidade por círculos em rede. Porto Alegre: Rede UNIDA; 2016. URL: http://hdl.handle.net/10183/142314 [accessed 2020-01-01]

12. Paglialonga A, Patel AA, Pinto E, Mugambi D, Keshavjee K. The Healthcare System Perspective in mHealth. $m \_H e a l t h$ Current and Future Applications 2005 Mar;33(3):194-206 [FREE Full text] [doi: 10.1007/978-3-030-02182-5 9]

13. Sullivan PS, Driggers R, Stekler JD, Siegler A, Goldenberg T, McDougal SJ, et al. Usability and Acceptability of a Mobile Comprehensive HIV Prevention App for Men Who Have Sex With Men: A Pilot Study. JMIR Mhealth Uhealth 2017 Mar 09;5(3):e26 [FREE Full text] [doi: 10.2196/mhealth.7199] [Medline: 28279949]

14. Hidalgo MA, Kuhns LM, Hotton AL, Johnson AK, Mustanski B, Garofalo R. The MyPEEPS randomized controlled trial: a pilot of preliminary efficacy, feasibility, and acceptability of a group-level, HIV risk reduction intervention for young men who have sex with men. Arch Sex Behav 2015 Feb;44(2):475-485 [FREE Full text] [doi: 10.1007/s 10508-014-0347-6] [Medline: 25135064]

15. Kuhns LM, Garofalo R, Hidalgo M, Hirshfield S, Pearson C, Bruce J, et al. A randomized controlled efficacy trial of an mHealth HIV prevention intervention for sexual minority young men: MyPEEPS mobile study protocol. BMC Public Health 2020 Jan 15;20(1):65 [FREE Full text] [doi: 10.1186/s12889-020-8180-4] [Medline: 31941475]

16. Montenegro L, Velasque L, LeGrand S, Whetten K, de Mattos Russo Rafael R, Malta M. Public Health, HIV Care and Prevention, Human Rights and Democracy at a Crossroad in Brazil. AIDS Behav 2020 Jan;24(1):1-4 [FREE Full text] [doi: 10.1007/s10461-019-02470-3] [Medline: 30903450]

17. Leshin D, Olshtain-Pops K, Moses A, Elinav H. Limited awareness of the effective timing of HIV post-exposure prophylaxis among people with high-risk exposure to HIV. Eur J Clin Microbiol Infect Dis 2019 Apr;38(4):779-784. [doi:

10.1007/s10096-019-03476-4] [Medline: 30680571] 
18. Queiroz AAFLN, Sousa AFLD, Brignol S, Araújo TME, Reis RK. Vulnerability to HIV among older men who have sex with men users of dating apps in Brazil. Braz J Infect Dis 2019;23(5):298-306 [FREE Full text] [doi: 10.1016/j.bjid.2019.07.005] [Medline: $\underline{31472125]}$

19. Gilbey D, Morgan H, Lin A, Perry Y. Effectiveness, Acceptability, and Feasibility of Digital Health Interventions for LGBTIQ+ Young People: Systematic Review. J Med Internet Res 2020 Dec 03;22(12):e20158 [FREE Full text] [doi: 10.2196/20158] [Medline: 33270039]

20. Patterson JG, Jabson JM, Bowen DJ. Measuring Sexual and Gender Minority Populations in Health Surveillance. LGBT Health 2017 Apr;4(2):82-105 [FREE Full text] [doi: 10.1089/lgbt.2016.0026] [Medline: 28287877]

21. Wadham E, Green C, Debattista J, Somerset S, Sav A. New digital media interventions for sexual health promotion among young people: a systematic review. Sex Health 2019 Apr;16(2):101-123. [doi: 10.1071/SH18127] [Medline: 30819326]

22. Nguyen MX, Krishnan A, Le GM, Nguyen QT, Bhadra NM, Nguyen SM, et al. The use of technology to find sexual health information online among men who have sex with men in Hanoi, Vietnam, 2016. Int J STD AIDS 2018 Apr;29(5):505-510. [doi: 10.1177/0956462417738680] [Medline: 29059034]

\author{
Abbreviations \\ INPI: National Institute of Industrial Property \\ mHealth: mobile health \\ PEP: postexposure prophylaxis \\ PrEP: pre-exposure prophylaxis \\ UNAIDS: Joint United Nations Program on HIV/AIDS \\ USPTO: United States Patent and Trademark Office
}

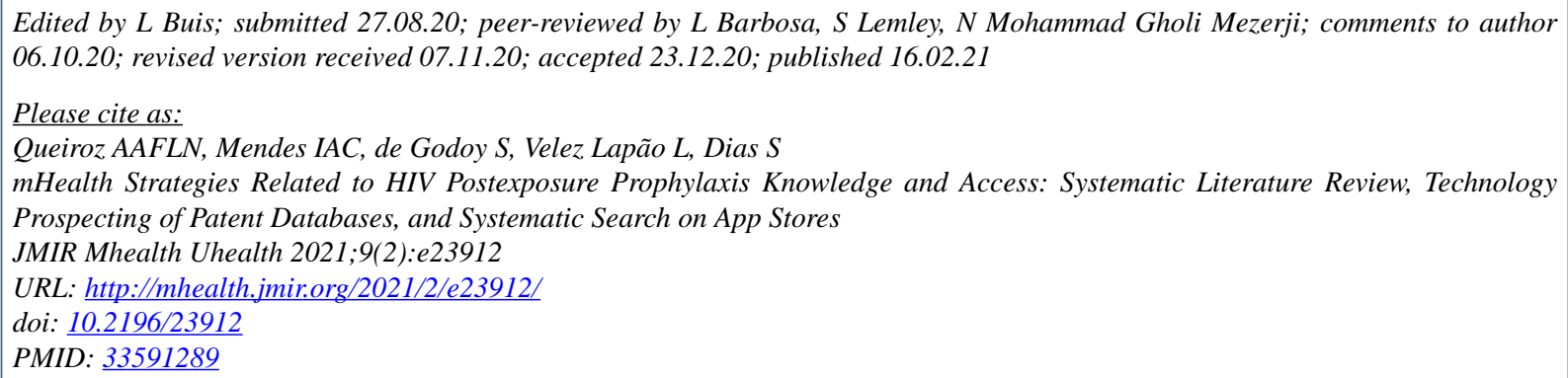

(C)Artur Acelino Francisco Luz Nunes Queiroz, Isabel Amélia Costa Mendes, Simone de Godoy, Luís Velez Lapão, Sónia Dias. Originally published in JMIR mHealth and uHealth (http://mhealth.jmir.org), 16.02.2021. This is an open-access article distributed under the terms of the Creative Commons Attribution License (https://creativecommons.org/licenses/by/4.0/), which permits unrestricted use, distribution, and reproduction in any medium, provided the original work, first published in JMIR mHealth and uHealth, is properly cited. The complete bibliographic information, a link to the original publication on http://mhealth.jmir.org/, as well as this copyright and license information must be included. 


\section{CONCLUSÃO}

$\mathrm{O}$ acesso à PEP possui barreiras que se organizam em diferentes dimensões e complexidade, afetando o serviço de saúde desde a ponta até niveis organizacionais e populacionais. Aspectos burocráticos, como a centralização da profilaxia em serviços específicos, criam barreiras físicas que impedem que as pessoas possam iniciá-la em tempo, além de contribuir para barreiras intangíveis, como preconceitos difundidos entre profissionais e usuários do serviço e até mesmo políticas públicas. A falta de conhecimento de seus usuários, e até mesmo profissionais, soma-se a esse panorama fazendo com que apenas uma pequena parcela receba o atendimento necessário e desejado.

O uso de tecnologias para superar essas barreiras foi uma das possibilidades apresentadas pelos entrevistados; no entanto, nossos dados apontam para mais uma lacuna: a falta de intervenções de saúde móvel para a PEP. Os aplicativos que existem ainda se concentram em fornecer informações sobre o HIV, e nenhuma iniciativa foi tomada para melhorar o acesso à outras intervenções de HIV. Esses aplicativos são profundamente focados no formato tradicional de compilar e organizar informações sobre o HIV, sem fornecer suporte para a ação.

A despeito de sua importância e possibilidades únicas de prevenção dentro do sistema de saúde, a PEP se mostra subestimada, seja pela falta de conhecimento, seja pelas estruturas limitantes de sua implementação. Os dados apresentados nesta pesquisa provêm subsídios que podem embasar mudanças necessárias para facilitar o acesso à profilaxia: a reformulação de políticas de distribuição e dispensação e o fomento à pesquisas para a integração de novas tecnologias. Nesse sentido, esta pesquisa contribui para subsidiar tomadores de decisão no delineamento de políticas públicas em saúde. 


\section{REFERÊNCIAS}

AMPARO, Keize Katiane dos Santos; RIBEIRO, Maria do Carmo Oliveira; GUARIEIRO, Lílian Lefol Nani. Estudo de caso utilizando mapeamento de prospecção tecnológica como principal ferramenta de busca científica. Perspectivas em Ciência da Informação, [S. l.], v. 17, n. 4, p. 195-209, 2012. DOI: 10.1590/S1413-99362012000400012. Disponível em: https://www.scielo.br/j/pci/a/TqkZ6MwqNMX7dSrsPvDwvLn/?lang=pt. Acesso em: 11 jul. 2021.

ANVISA. Guia de validação de sistemas computadorizados.pdf - Português (Brasil). 2020. Disponível em: https://www.gov.br/anvisa/pt-

br/centraisdeconteudo/publicacoes/medicamentos/publicacoes-sobre-medicamentos/guia-devalidacao-de-sistemas-computadorizados.pdf/view. Acesso em: 11 jul. 2021.

BEKKER, Linda-Gail et al. Advancing global health and strengthening the HIV response in the era of the Sustainable Development Goals: the International AIDS Society-Lancet Commission. The Lancet, [S. l.], v. 392, n. 10144, p. 312-358, 2018. DOI: 10.1016/S01406736(18)31070-5. Disponível em:

https://www.thelancet.com/journals/lancet/article/PIIS0140-6736(18)31070-5/fulltext.

Bibliography

BRASIL. Aplicativos | Departamento de Doenças de Condições Crônicas e Infecções

Sexualmente Transmissíveis. [s.d.]. Disponível em: http://www.aids.gov.br/pt-br/centraisde-conteudos/aplicativos.

BRASIL. Indicadores e Dados Básicos do HIV/AIDS nos Municípios Brasileiros. [s.d.]. Disponível em: http://indicadores.aids.gov.br/.

BRASIL. O que é PEP? | Departamento de Doenças de Condições Crônicas e Infecções

Sexualmente Transmissíveis. 2017. Disponível em: http://www.aids.gov.br/o_que_e_pep.

Acesso em: 11 jul. 2021.

BRASIL. Protocolo Clínico e Diretrizes Terapêuticas para Profilaxia Pós-Exposição (PEP) de Risco à Infecção pelo HIV, IST e Hepatites Virais. 2015. Disponível em: http://www.aids.gov.br/pt-br/pub/2015/protocolo-clinico-e-diretrizes-terapeuticas-paraprofilaxia-pos-exposicao-pep-de-risco.

BRITO, Ana Maria De; CASTILHO, Euclides Ayres De; SZWARCWALD, Célia Landmann. AIDS e infecção pelo HIV no Brasil: uma epidemia multifacetada. Revista da Sociedade

Brasileira de Medicina Tropical, [S. l.], v. 34, n. 2, p. 207-217, 2001. DOI: 10.1590/s003786822001000200010. Disponível em:

https://www.scielo.br/j/rsbmt/a/zBSKHBDyfvfz7cLQp7fsSBg/?lang=pt. Acesso em: 1 jun. 2021.

BURTON, Matthew J. et al. The Lancet Global Health Commission on Global Eye Health: vision beyond 2020. The Lancet Global Health, [S. l.], v. 9, n. 4, p. e489-e551, 2021. DOI: 10.1016/S2214-109X(20)30488-5. Disponível em:

https://www.thelancet.com/journals/langlo/article/PIIS2214-109X(20)30488-5/fulltext.

Acesso em: 29 mar. 2021.

CASTRO, Rodolfo et al. The Men Who Have Sex with Men HIV Care Cascade in Rio de Janeiro, Brazil. PLOS ONE, [S. l.], v. 11, n. 6, p. e0157309, 2016. DOI:

10.1371/journal.pone.0157309. Acesso em: 11 jul. 2021.

CENTRO REGIONAL DE ESTUDOS PARA O DESENVOLVIMENTO DA SOCIEDADE DA INFORMAÇÃO (CETIC.BR.). TIC Governo Eletrônico. [s.d.]. Disponível em: http:/cetic.br/pesquisa/governo-eletronico/indicadores. Acesso em: 11 jul. 2021.

COHEN, Stephanie E.; LIU, Albert Y.; BERNSTEIN, Kyle T.; PHILIP, Susan. Preparing for HIV Pre-Exposure Prophylaxis. American Journal of Preventive Medicine, [S. l.], v. 44, n. 1, p. S80-S85, 2013. DOI: 10.1016/j.amepre.2012.09.036. Acesso em: 11 jul. 2021. 
COSTA, Ana Maria; RIZZOTTO, Maria Lucia Frizon; LOBATO, Lenaura de Vasconcelos Costa. Na pandemia da Covid-19, o Brasil enxerga o SUS. Saúde em Debate, [S. l.], v. 44, n. 125, p. 289-296, 2020. DOI: 10.1590/0103-1104202012500. Disponível em: https://www.scielosp.org/pdf/sdeb/2020.v44n125/289-296/pt. Acesso em: 23 dez. 2020. DOLEZAL, Curtis; FRASCA, Timothy; GIGUERE, Rebecca; IBITOYE, Mobolaji; CRANSTON, Ross D.; FEBO, Irma; MAYER, Kenneth H.; MCGOWAN, Ian; CARBALLODIÉGUEZ, Alex. Awareness of Post-Exposure Prophylaxis (PEP) and Pre-Exposure Prophylaxis (PrEP) Is Low but Interest Is High Among Men Engaging in Condomless Anal Sex with Men in Boston, Pittsburgh, and San Juan. AIDS Education and Prevention, [S. l.], v. 27, n. 4, p. 289-297, 2015. DOI: 10.1521/aeap.2015.27.4.289. Acesso em: 5 maio. 2020. DRIESSNACK, M.;SOUSA, V. D.; MENDES, I.A.C. Revisão dos desenhos de pesquisa relevantes para enfermagem: Parte 3: Métodos mistos e múltiplos. Revista Latino-Americana de Enfermagem, v. 15, n. 5, p. 1046-1049, 2007.

ESTRIN, D.; SIM, I. Open mHealth Architecture: An Engine for Health Care Innovation. Science, [S. l.], v. 330, n. 6005, p. 759-760, 2010. DOI: 10.1126/science.1196187. Acesso em: 9 ago. 2020.

FIORDELLI, Maddalena; DIVIANI, Nicola; SCHULZ, Peter J. Mapping mHealth Research: A Decade of Evolution. Journal of Medical Internet Research, [S. l.], v. 15, n. 5, p. e95, 2013. DOI: 10.2196/jmir.2430.

FOOD AND DRUG ADMINISTRATION. Mobile Medical Applications; Guidance for Industry and Food and Drug Administration Staff; Availability. 2013. Disponível em: https://www.federalregister.gov/documents/2013/09/25/2013-23293/mobile-medicalapplications-guidance-for-industry-and-food-and-drug-administration-staff. Acesso em: 11 jul. 2021.

FREE, Caroline; PHILLIPS, Gemma; FELIX, Lambert; GALLI, Leandro; PATEL, Vikram; EDWARDS, Philip. The effectiveness of M-health technologies for improving health and health services: a systematic review protocol. BMC Research Notes, [S. l.], v. 3, n. 1, 2010. DOI: 10.1186/1756-0500-3-250.

GUIMARÃES, Reinaldo. Technological incorporation in the Unified Health System (SUS): the problem and ensuing challenges. Ciência \& Saúde Coletiva, [S. l.], v. 19, n. 12, p. 48994908, 2014. DOI: 10.1590/1413-812320141912.04642014. Acesso em: 11 dez. 2019. HAJIZADEH, Mohammad; EDMONDS, Sterling. Universal Pharmacare in Canada: A Prescription for Equity in Healthcare. International Journal of Health Policy and Management, [S. l.], v. 9, n. 3, p. 91-95, 2019. DOI: 10.15171/ijhpm.2019.93. HOCH, Dan; FERGUSON, Tom. What I've Learned from E-Patients. PLoS Medicine, [S. l.], v. 2, n. 8, p. e206, 2005. DOI: 10.1371/journal.pmed.0020206. Acesso em: 17 jan. 2020. IWAYA, L. H. et al. Mobile health in emerging countries: A survey of research initiatives in Brazil. International Journal of Medical Informatics, [S. l.], v. 82, n. 5, p. 283-298, 2013. DOI: 10.1016/j.ijmedinf.2013.01.003. Acesso em: 11 jul. 2021.

KAGOTHO, Njeri; SSEWAMALA, Fred M. Correlates of depression among caregivers of children affected by HIV/AIDS in Uganda: Findings from the Suubi-Maka Family Study.

AIDS Care, [S. l.], v. 24, n. 10, p. 1226-1232, 2012. DOI: 10.1080/09540121.2012.658754. Acesso em: 9 ago. 2020.

LEGIDO-QUIGLEY, Helena et al. Are high-performing health systems resilient against the COVID-19 epidemic? The Lancet, [S. l.], v. 395, n. 10227, p. 848-850, 2020. DOI: 10.1016/S0140-6736(20)30551-1. Disponível em: https:/www.thelancet.com/journals/lancet/article/PIIS0140-6736(20)30551-1/fulltext. LEVI, Jacob; RAYMOND, Alice; POZNIAK, Anton; VERNAZZA, Pietro; KOHLER, Philipp; HILL, Andrew. Can the UNAIDS 90-90-90 target be achieved? A systematic analysis of national HIV treatment cascades. BMJ Global Health, [S. l.], v. 1, n. 2, p. e000010, 2016. DOI: 10.1136/bmjgh-2015-000010. Disponível em: https://gh.bmj.com/content/1/2/e000010. Acesso em: 5 jul. 2019. 
LUZ, Paula M.; VELOSO, Valdilea G.; GRINSZTEJN, Beatriz. The HIV epidemic in Latin America. Current Opinion in HIV and AIDS, [S. l.], v. 14, n. 5, p. 366-373, 2019. DOI: 10.1097/coh.0000000000000564. Acesso em: 10 jun. 2020.

MAKSUD, Ivia; FERNANDES, Nilo Martinez; FILGUEIRAS, Sandra Lucia; MAKSUD, Ivia; FERNANDES, Nilo Martinez; FILGUEIRAS, Sandra Lucia. Technologies for HIV prevention and care: challenges for health services. Revista Brasileira de Epidemiologia, [S. l.], v. 18, n. Suppl 1, p. 104-119, 2015. DOI: 10.1590/1809-4503201500050008. Disponível em: http://www.scielo.br/scielo.php?script=sci_arttext\&pid=S1415-790X2015000500104. Acesso em: 16 dez. 2020.

MASSUDA, Adriano; HONE, Thomas; LELES, Fernando Antonio Gomes; DE CASTRO, Marcia C.; ATUN, Rifat. The Brazilian health system at crossroads: progress, crisis and resilience. BMJ Global Health, [S. l.], v. 3, n. 4, p. e000829, 2018. DOI: 10.1136/bmjgh2018-000829. Disponível em: https://www.ncbi.nlm.nih.gov/pmc/articles/PMC6035510/.

MAYER, Kenneth H. et al. The persistent and evolving HIV epidemic in American men who have sex with men. The Lancet, [S. l.], v. 397, n. 10279, p. 1116-1126, 2021. DOI:

10.1016/S0140-6736(21)00321-4. Disponível em:

https://www.thelancet.com/journals/lancet/article/PIIS0140-6736(21)00321-4/fulltext. Acesso em: 11 jul. 2021.

MECHAEL, Patricia. Barriers and gaps affecting mHealth in low and middle income countries : policy white paper. bibalex.org, [S. l.], 2010. Disponível em:

http://bibalex.org/baifa/en/resources/document/452419.

MURAKAMI, A. et al. Acesso a informações médicas através do uso de sistemas de computação móvel. In: Congresso Brasileiro de Informática na Saúde. 2004. p. 2004. NW, 1615 L. St; SUITE 800WASHINGTON; INQUIRIES, DC 20036USA202-419-4300 | Main202-857-8562 | Fax202-419-4372 | Media. Smartphone Ownership 2013. 2013. Disponível em: https://www.pewresearch.org/internet/2013/06/05/smartphone-ownership$2013 /$.

ORTBLAD, Katrina F.; LOZANO, Rafael; MURRAY, Christopher J. L. The burden of HIV. AIDS, [S. l.], v. 27, n. 13, p. 2003-2017, 2013. DOI: 10.1097/qad.0b013e328362ba67. Acesso em: 27 maio. 2019.

PHILLIPS, Gregory et al. Addressing the Disproportionate Impacts of the COVID-19 Pandemic on Sexual and Gender Minority Populations in the United States: Actions Toward Equity. LGBT Health, [S. l.], v. 7, n. 6, 2020. DOI: 10.1089/lgbt.2020.0187.

ROTAROU, Elena S.; SAKELLARIOU, Dikaios. Neoliberal reforms in health systems and the construction of long-lasting inequalities in health care: A case study from Chile. Health Policy, [S. l.], v. 121, n. 5, p. 495-503, 2017. DOI: 10.1016/j.healthpol.2017.03.005. SAID, Amanda Pinheiro; SEIDL, Eliane Maria Fleury. Sorodiscordância e prevenção do HIV: percepções de pessoas em relacionamentos estáveis e não estáveis. Interface Comunicação, Saúde, Educação, [S. l.], v. 19, n. 54, p. 467-478, 2015. DOI: 10.1590/180757622014.0120. Disponível em:

https://www.scielo.br/j/icse/a/gq7kVkcmhcdthZ9F6hhxk9F/abstract/?lang=pt. Acesso em: 11 jul. 2021.

SANTOS, Marcio de Miranda; COELHO, Gilda Massari; SANTOS, Dalci Maria Dos; FELLOWS FILHO, Lélio. Prospecção de tecnologias de futuro: métodos, técnicas e abordagens. Parcerias Estratégicas, [S. l.], v. 9, n. 19, p. 189-230, 2010. Disponível em: http://seer.cgee.org.br/index.php/parcerias_estrategicas/article/view/253. Acesso em: 11 jul. 2021.

SCHECHTER, Mauro. Profilaxia pré e pós-exposição: o uso de drogas antirretrovirais para a prevenção da transmissão sexual da infecção pelo HIV. The Brazilian Journal of Infectious Diseases, [S. l.], v. 2, n. 4, p. 112-117, 2016. Disponível em: https://www.bjid.org.br/enprofilaxia-pre-e-pos-exposicao-o-articulo-X2177511716574480. Acesso em: 11 jul. 2021. SOUSA, George Jó Bezerra; GARCES, Thiago Santos; CESTARI, Virna Ribeiro Feitosa; 
MOREIRA, Thereza Maria Magalhães; FLORÊNCIO, Raquel Sampaio; PEREIRA, Maria Lúcia Duarte. Estimation and prediction of COVID-19 cases in Brazilian metropolises*. Revista Latino-Americana de Enfermagem, [S. l.], v. 28, 2020. DOI: 10.1590/15188345.4501.3345. Disponível em:

https://www.scielo.br/j/rlae/a/4CrffCHXJDc7knVDz9CwDrt/?lang=en.

SZELEWA, Dorota. Recurring ideas: Searching for the roots of right-wing populism in Eastern Europe. European Journal of Cultural Studies, [S. l.], p. 136754942092140, 2020. DOI: 10.1177/1367549420921400. Acesso em: 17 jul. 2020.

TANNE, Janice Hopkins; HAYASAKI, Erika; ZASTROW, Mark; PULLA, Priyanka; SMITH, Paul; RADA, Acer Garcia. Covid-19: how doctors and healthcare systems are tackling coronavirus worldwide. BMJ, [S. l.], p. m1090, 2020. DOI: 10.1136/bmj.m1090. TRICKEY, Adam et al. Survival of HIV-positive patients starting antiretroviral therapy between 1996 and 2013: a collaborative analysis of cohort studies. The Lancet HIV, [S. l.], v. 4, n. 8, p. e349-e356, 2017a. DOI: 10.1016/s2352-3018(17)30066-8. Acesso em: 21 abr. 2020.

UNAIDS, JOINT UNITED NATIONS PROGRAM HIV/AIDS. EVIDENCE REVIEW: IMPLEMENTATION OF THE 2016-2021 UNAIDS STRATEGY ON THE FASTTRACK TO END AIDS Agenda item 8 UNAIDS/PCB (47)/CRP3. [s.1.] : , 2020. Acesso em: 11 jul. 2021.

UNAIDS, JOINT UNITED NATIONS PROGRAM HIV/AIDS. Rights in the time of COVID-19 - Lessons from HIV for an effective, community-led response. 2020. Disponível em: https:/www.unaids.org/en/resources/documents/2020/human-rights-andcovid-19. Acesso em: 11 jul. 2021.

UNAIDS, JOINT UNITED NATIONS PROGRAM HIV/AIDS. UNAIDS data 2020. 2020.

Disponível em: https://www.unaids.org/en/resources/documents/2020/unaids-data. WHITLOCK, G. et al. Should MSM attending for PEP be offered PrEP?: P56. Hiv Medicine, v. 17, 2016.

WILSON L., MENDES I.A.C., KLOPPER H., CATRAMBONE C., AL-MAAITAH R., NORTON M.E. \& HILL M. (2016) 'Global health' and 'global nursing': proposed definitions from The Global Advisory Panel on the Future of Nursing. Journal of Advanced Nursing 00 (0), 000-000. doi: 10.1111/jan.12973

WHO GLOBAL OBSERVATORY FOR EHEALTH. mHealth: new horizons for health through mobile technologies: second global survey on eHealth. 2011. Disponível em: http://apps.who.int/iris/handle/10665/44607. Acesso em: 11 jul. 2021.

WORLD HEALTH ORGANIZATION. The world health report: health systems financing: the path to universal coverage. [s.1.] : World Health Organization, 2010. Disponível em: https://apps.who.int/iris/handle/10665/44371.

WU, Yi-Chi; CHEN, Ching-Sung; CHAN, Yu-Jiun. Overview of The 2019 Novel Coronavirus (2019-nCoV). Journal of the Chinese Medical Association, [S. l.], v. 83, n. 3, p. 1, 2020. DOI: 10.1097/jcma.0000000000000270. 
ANEXOS 
Anexo A- Aprovação do Comitê de Ética

\section{USP - ESCOLA DE ENFERMAGEM DE RIBEIRÃO PRETO DA USP}

\section{PARECER CONSUBSTANCIADO DO CEP}

\section{DADOS DO PROJETO DE PESQUISA}

Título da Pesquisa: DESENVOLVIMENTO DE UM APLICATIVO PARA IDENTIFICAÇÃO, TRIAGEM E ENCAMINHAMENTO DE PESSOAS EXPOSTAS SEXUALMENTE AO HIV

Pesquisador: Artur Acelino Francisco Luz Nunes Queiroz

Area Temática:

Versăo: 2

CAAE: 08198819.2.0000.5393

Instituiçăo Proponente: Escola de Enfermagem de Ribeiräo Preto - USP

Patrocinador Principal: Financiamento Proprio

\section{DADOS DO PARECER}

Número do Parecer: 3.280 .490

\section{Apresentação do Projeto:}

Trata-se da reapresentação de um projeto de pesquisa que visa desenvolver e validar um aplicativo para smartphone voltado à identificação, triagem e encaminhamento de pessoas expostas sexualmente ao HIV. Para isso propõe uma pesquisa multi-método de criação e avaliação de tecnologia baseada no paradigma construtivista, realizada em seis etapas consecutivas: 1- Prospecção, Revisão e Análise dos aplicativos voltados ao paciente cirúrgico; 2- revisão integrativa sobre as complicaçōes pós-aita comuns a pacientes cirúrgico; 3- Definição de conteúdo do aplicativo e avaliação por experts (validação); 4-Desenvolvimento do aplicativo e 5-Avaliaçáo do aplicativo por especialistas. Consta de uma etapa qualitativa, a ser realizada com 10 participantes, profissionais das Secretaria Municipal da Saûde de Ribeiräo Preto para levantamento dos temas relevantes para compor o aplicativo; $e$ de uma etapa de validaçăo, realizada com 10 especialistas ligados ao ensino, pesquisa $\theta$ a assistència a saúde, levando em consideração sua experiència e qualificaçăo na área a ser estudada.

\section{Objetivo da Pesquisa:}

0 objetivo da pesquisa é "Desenvolver e validar um aplicativo para smartphone voltado a identificaçẫo, triagem e encaminhamento de pessoas expostas sexualmente ao HIV." Apresenta como objetivos especificos: "Identificar tecnologias eletrónicas móveis disponiveis para a identificaçăo, triagem e encaminhamento de pessoas expostas sexualmente ao HIV para serviços 


\section{USP-ESCOLA DE ENFERMAGEM DE RIBEIRÃO PRETO DA USP}

Continue,ăa do Parecer. 3280.490

\section{Recomendaçōes:}

Não há

Conclusỏes ou Pendências e Lista de Inadequaçōes:

Não há

Consideraçōes Finais a critério do CEP:

Parecer aprovado ad referendum

Este parecer foi elaborado baseado nos documentos abaixo relacionados:

\begin{tabular}{|c|c|c|c|c|}
\hline Tipo Documento & Arquivo & Postagem & Autor & Situação \\
\hline $\begin{array}{l}\text { Informaçóes Básicas } \\
\text { do Projelo }\end{array}$ & $\begin{array}{l}\text { PB_INFORMACCOES_BASICAS_DO_P } \\
\text { ROJETO 1246599.pdI }\end{array}$ & $\begin{array}{l}12 / 04 / 2019 \\
12: 21: 55 \\
\end{array}$ & & Aceito \\
\hline Outros & oficiocep2.pdf & $\begin{array}{c}12 / 04 / 2019 \\
12: 21: 15\end{array}$ & $\begin{array}{l}\text { Artur Acelino } \\
\text { Francisco Luz Nunes } \\
\text { Queitoz }\end{array}$ & Aceito \\
\hline $\begin{array}{l}\text { TCLE / Termos de } \\
\text { Assentimento / } \\
\text { Justificativa de } \\
\text { Ausència }\end{array}$ & tcleart02.pdf & $\begin{array}{c}12 / 04 / 2019 \\
12: 20: 21\end{array}$ & $\begin{array}{l}\text { Artur Acelino } \\
\text { Francisco Luz Nunes } \\
\text { Queiroz }\end{array}$ & Aceillo \\
\hline $\begin{array}{l}\text { TCLE / Termos de } \\
\text { Assentimento / } \\
\text { Justificativa de } \\
\text { Auséncia } \\
\end{array}$ & tcleart.pdf & $\begin{array}{l}12 / 04 / 2019 \\
12: 19: 56\end{array}$ & \begin{tabular}{|l|} 
Artur Acelino \\
Francisco Luz Nunes \\
Queiroz
\end{tabular} & Aceito \\
\hline Folha de Rosto & folhaderostovertic.pdf & $\begin{array}{c}19 / 02 / 2019 \\
15: 36: 33\end{array}$ & \begin{tabular}{|l|} 
Artur Acelino \\
Francisco Luz Nunes \\
Queiroz
\end{tabular} & Aceilo \\
\hline $\begin{array}{l}\text { Projeto Detalhado I } \\
\text { Brochura } \\
\text { Investigador }\end{array}$ & PROJETO_CEP.pdf & $\begin{array}{c}19 / 02 / 2019 \\
15: 29: 56\end{array}$ & \begin{tabular}{|l|} 
Artur Acelino \\
Francisco Luz Nunes \\
Queitoz
\end{tabular} & Aceito \\
\hline Outros & prefeitura.pdl & $\begin{array}{c}18 / 02 / 2019 \\
17: 57: 11\end{array}$ & \begin{tabular}{|l|} 
Artur Acelino \\
Francisco Luz Nunes \\
Queiroz
\end{tabular} & Aceilo \\
\hline Orçamento & ORCAMENTO_CEP2.pdf & $\begin{array}{c}01 / 02 / 2019 \\
14: 07: 13\end{array}$ & $\begin{array}{l}\text { Artur Acelino } \\
\text { Francisco Luz Nunes } \\
\text { Oueitoz }\end{array}$ & Aceilo \\
\hline Cronograma & Cronograma_CEP.pdf & $\begin{array}{c}31 / 01 / 2019 \\
10: 37: 23\end{array}$ & $\begin{array}{l}\text { Artur Acelino } \\
\text { Francisco Luz Nunes } \\
\text { Queiroz }\end{array}$ & Aceito \\
\hline
\end{tabular}

